MATHEMATICA CENTER FOR STUDYING DISABILITY POLICY

\title{
Trends in Medical Conditions and Functioning in the U.S. Population, 1997-2017
}

\section{September 16, 2019}

\author{
Anna Hill* \\ Purvi Sevak
}

\section{*Corresponding author's contact information:}

Mathematica

955 Massachusetts Avenue

Cambridge, MA 02139

Telephone: (617) 715-6957

Email: ahill@mathematica-mpr.com

Reference Number: 40112.D-MP-18-Q4

The research reported herein was performed pursuant to a grant from the U.S. Social Security Administration (SSA) funded as part of the Disability Research Consortium. The opinions and conclusions expressed are solely those of the authors and do not represent the opinions or policy of SSA or any agency of the Federal Government. Neither the United States Government nor any agency thereof, nor any of their employees, makes any warranty, expressed or implied, or assumes any legal liability or responsibility for the accuracy, completeness, or usefulness of the contents of this report. Reference herein to any specific commercial product, process, or service by trade name, trademark, manufacturer, or otherwise does not necessarily constitute or imply endorsement, recommendation or favoring by the United States Government or any agency thereof. 
This page has been left blank for double-sided copying. 


\section{CONTENTS}

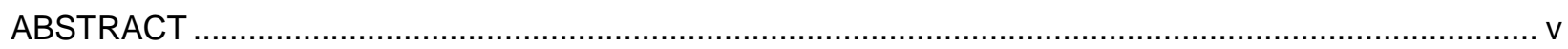

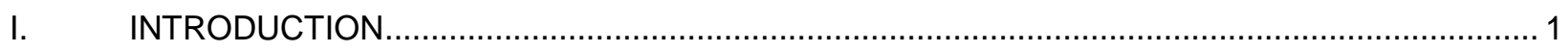

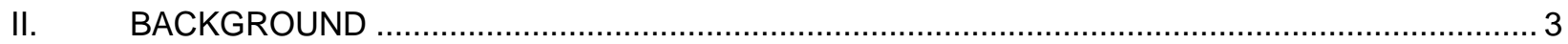

A. Federal disability programs and increase in program participation over time ......................... 3

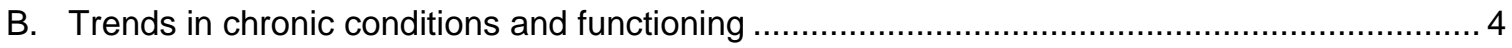

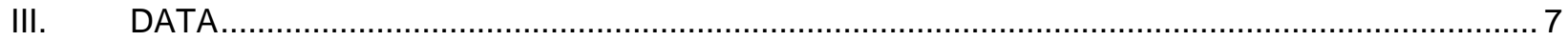

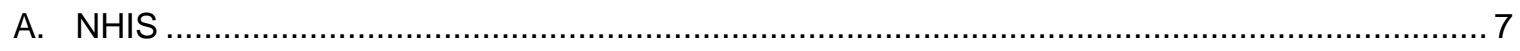

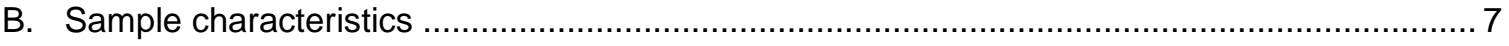

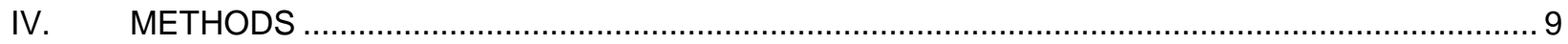

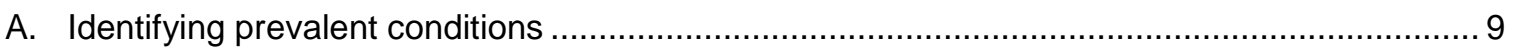

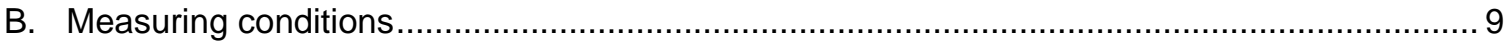

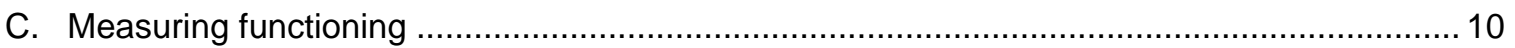

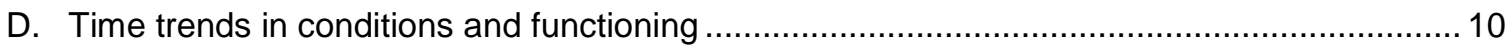

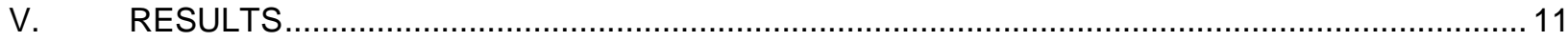

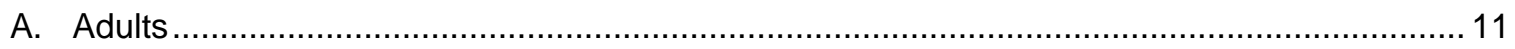

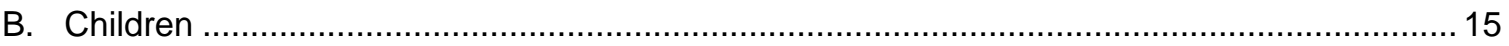

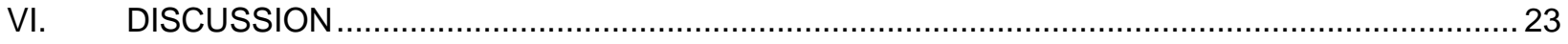

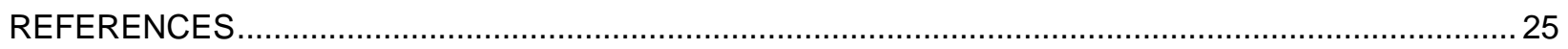

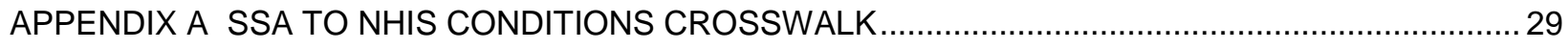

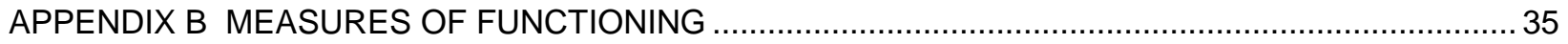

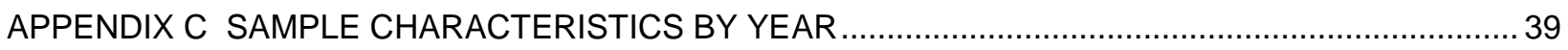


This page has been left blank for double-sided copying. 


\section{ABSTRACT}

\section{Project Number}

D-MP-18-Q4

\section{Title}

Trends in medical conditions and functioning in the U.S. population, 1997-2017

\section{Authors}

Anna Hill and Purvi Sevak

\section{Date}

March 29, 2019

\section{Key Findings and Policy Implications}

Over the last several decades, the federal disability rolls grew substantially, though this growth has slowed more recently. Many factors underlie these trends, including changes in demographics, policies, and disability prevalence. In this study, we use nationally representative survey data from the National Health Interview Survey (NHIS) to document trends since 1997 in the most commonly disabling chronic conditions and functional limitations. We find that the prevalence of several conditions has increased in the U.S. population - most notably, obesity, endocrine conditions, and neoplasms among adults, and autism, developmental and intellectual disabilities, and skin conditions among children. We also find notable changes in functional limitations. Although hearing and vision limitations declined, adults experienced increases in cognitive, social, and movement limitations, and children experienced an increase in school limitations. These changes in condition prevalence and functional limitations are consistent with some but not all observed changes in the federal disability rolls. An understanding of these trends can be helpful in planning for future demand of disability benefits. 
This page has been left blank for double-sided copying. 


\section{INTRODUCTION}

Over the last several decades, the federal disability rolls grew substantially, with applications and awards increasing through the Great Recession. The rate of this growth has slowed more recently, with declines in both applications and awards (Center for Budget and Policy Priorities 2018). During this period, there have been increases in the proportion of awards made on the basis of certain disabling conditions, including "hard-to-verify" conditions such as lower back pain, arthritis, and mental illness, and autism and attention deficit hyperactivity disorder (ADHD) among children (National Academies of Sciences, Engineering, and Medicine 2015; Autor and Duggan 2006; Liebman 2015). ${ }^{1}$ Increases in the population prevalence of these conditions could be driving these trends. However, the extent to which medical conditions become disabling to the level required for receipt of federal disability benefits reflects numerous factors, including the likelihood of a timely diagnosis, efficacy of medical treatments, cooccurrence of other conditions, and the willingness of employers to hire and accommodate workers with disabling conditions. Many of these factors have changed over the last several decades.

The growth and changing composition of Social Security Administration (SSA) disability beneficiaries provide the backdrop for this study. We examine one of the many factors that could account for these trends: trends in the population prevalence of potentially disabling conditions. Although earlier studies have documented trends in conditions among beneficiaries, because the studies have been limited to administrative data on beneficiaries, they have not examined whether prevalence in the national population has evolved over time.

We also address how the functioning of individuals with these conditions has changed over time. An examination of functioning is important because it can shed light on the extent to which growth and composition of beneficiaries reflect increases in condition prevalence versus declines in functioning. This in turn has implications for supports and interventions to help individuals with these conditions. For example, suppose the prevalence of a condition remained constant over two decades, but functioning among the group with the condition became substantially worse. This pattern might signal that policymakers consider interventions that could mitigate some of the functional challenges as a way to curb growth in the rolls. In contrast, increases in prevalence without declines in functioning among those with a particular condition might suggest that more fundamental changes are occurring in the health of the population, and SSA and policymakers may have more limited control over these changes.

Our analysis is descriptive in nature, as our intention is to document trends in the conditions and functional limitations that could be contributing to changes in the beneficiary population. We control for composition of the age, gender, and race of the population when estimating trends. This methodological approach allows us to attribute any trends as real changes in prevalence, as opposed to just a reflection of population aging or other demographic changes. Our findings suggest that some share of the trends in composition of conditions among SSA beneficiaries can be explained by prevalence of conditions in the population, even after age and demographic

\footnotetext{
1 "Hard-to-verify" is a term used by Liebman (2015) to highlight the difficulty in determining whether the constellation of impairments alleged by applicants can be easily measured. The term is not intended to suggest fraudulent allegations by applicants.
} 
adjustments, particularly among children. We find that the prevalence of some conditions has fallen, whereas the prevalence of other conditions, including obesity and endocrine disorders among adults and respiratory and developmental conditions among children, has increased. We also find increases in several domains of functional limitations, including cognitive limitations, social limitations, and movement limitations among adults, and school limitations among children. The declines in functioning among adults suggest that the increasing composition of disability beneficiaries with musculoskeletal and mood disorders could be more a result of declines in functioning rather than increases in condition prevalence. 


\section{BACKGROUND}

\section{A. Federal disability programs and increase in program participation over time}

The Social Security Administration provides cash support to children and adults with disabilities through two programs, the Supplemental Security Income (SSI) program and the Social Security Disability Insurance (SSDI) program. SSI provides cash benefits to poor individuals who are blind, have a disability, or are age 65 or older. SSDI beneficiaries are primarily ages 18 to 67 ( 67 being the full retirement age for Social Security retirement benefits). SSDI eligibility and SSI eligibility for children and non-elderly adults both include a stringent medical disability determination process, though the financial eligibility criteria differ across programs. For adult applicants, this multi-step process must reveal that the applicant is unable to engage in substantial gainful activity or employment because of a medically determinable physical or mental impairment that is expected to last at least 12 months or result in death. For child SSI applicants to be deemed medically eligible, the process must reveal a medically determinable physical or mental impairment that results in severe functional limitations and is expected to last at least 12 months or result in death. SSI benefits are means-tested based on income and assets, with set maximum monthly payment levels (currently \$771). SSDI benefits are not means-tested, but they are available only to individuals who have contributed to the program's trust fund through a sufficiently long recent work history, and benefit levels depend on prior earnings levels.

Although these programs provide important income replacement for individuals with disabilities, in recent decades policymakers and researchers have raised a number of concerns about the programs. First, the programs create disincentives to work among potential applicants and disincentives to return to work among existing beneficiaries. At the same time, benefit levels are low enough to leave many beneficiaries living in poverty. These concerns likely expanded due to substantial growth in the federal disability rolls and concerns about the solvency of the SSDI trust fund over the past several decades. For example, the share of adults receiving SSDI benefits more than doubled from 2.2\% in the late 1970s to 4.6\% in 2013 (Liebman 2015). Among children, participation in the SSI program rose 55\% between 2000 and 2012 (Schmidt and Sevak 2017).

Concurrent with the growth in disability benefit receipt, certain conditions have represented a growing share of awards. Of particular interest are "hard-to-verify" conditions such as lower back pain, arthritis, and mental illness among adults, and autism and ADHD among children (National Academies of Sciences, Engineering, and Medicine 2015; Autor and Duggan 2006; Liebman 2015). ${ }^{2}$ The share of workers who were awarded SSDI benefits on the basis of musculoskeletal conditions more than doubled, from less than $20 \%$ in the early 1980 s to over $40 \%$ in recent years (Anand and Ben-Shalom 2017). Similarly, the share of workers awarded

\footnotetext{
2 "Hard-to-verify" is a term used by Liebman (2015) to highlight the difficulty in determining whether the constellation of impairments alleged by applicants can be easily measured. The term is not intended to suggest fraudulent allegations by applicants.
} 
benefits for mental impairments nearly doubled from 10\% in 1981 to $18 \%$ in 2012 (Sevak and Khan 2017).

Growth in the disability rolls has leveled off since 2014 (SSA 2006), but concerns remain about rates of receipt, program solvency, and the well-being of beneficiaries. Researchers have identified a number of reasons for the growth, but no comprehensive assessment identifies the magnitude of each factor. Although some researchers claim that a majority of the increase in adult SSDI receipt can be attributed to population growth, the aging of the baby boom cohort, and the increase in female labor force participation (Liebman 2015; Pattison and Waldron 2013; Reno 2011), a number of researchers have identified other factors that drove that historical growth. Some share of the earlier growth and change in composition of disabling conditions likely reflects SSA policy changes for adult beneficiaries in the 1980s (Autor and Duggan 2006) and for child SSI beneficiaries in the 1990s (U.S. GAO 2012). The Great Recession also led to an increase in applications, though studies differ in the extent to which they found it increased awards (Nichols et al. 2017; Rupp 2012; Manchester and Song 2011). Finally, increases in disability rates over time explain a small but significant $6 \%$ of the growth in benefit receipt among adults (Pattison and Waldron 2013). Among children, increases in SSI participation can be partly explained by large increases in ADHD diagnoses (Schmidt and Sevak 2017) and increases in the prevalence of impairments more broadly (National Academies of Sciences, Engineering, and Medicine 2015).

Hypothesized explanations for the recent plateau and decline in applications and awards are more limited. First, the demographic changes that contributed to prolonged program growth, the increase in labor force participation of married women, and the baby boom cohort reaching midlife have all ended, thus contributing to an expected stabilization of new applicants (Center for Budget and Policy Priorities 2018). Second, the slow but steady economic expansion that began with the recovery from the Great Recession has contributed to the decline in applications. Finally, there is evidence that SSA practices, including closing field offices where individuals apply for benefits (Deshpande and Li 2017) and tightening the appeal process for individuals who do not initially clear the disability determination process, have led to reductions in applications and awards (Schwartz 2018).

In this study, we contribute to this literature by examining one of the many factors that could account for these trends: changes in the prevalence of potentially disabling conditions and changes in functioning. Before describing our approach, we first provide an overview of the existing literature on condition prevalence and functioning.

\section{B. Trends in chronic conditions and functioning}

Improvements in prevention, early diagnoses, and treatment have meant that adult rates of mortality from some chronic conditions have fallen. For example, between 2000 and 2014, decreases in death rates due to heart disease, cancer, and stroke contributed toward increasing life expectancy. Simultaneously, however, increases in death rates due to hypertension, chronic liver disease, and suicide have contributed toward declines in life expectancy (Kochanek et al. 2016). Although these are not measures of prevalence, this information on cause of death provides some insight on improvements in some conditions such as heart disease, as well as increasing prevalence in addiction and mental illness, for which reliable prevalence data are not 
readily available. A study of hospital discharges from a slightly earlier period, 1995 to 2002, found increases in the share of discharges due to mental illness that are consistent with these findings (Watanabe-Galloway and Zhang, 2007).

The most dramatic increases in prevalence concern diabetes, obesity, and pain. The prevalence of type 2 diabetes, estimated to be $14 \%$ in 2011/2012, was $27 \%$ higher than ageadjusted rates in 1988, with increases among all race, ethnic, gender, educational, and income groups (Menke et al. 2015). Rising obesity rates can cause or aggravate musculoskeletal conditions and other conditions and disabilities (Alley et al. 2008; Schimmel Hyde 2016; Sturm et al. 2004; Viester et al. 2013). Musculoskeletal conditions themselves contribute to rising rates of pain. Case and Deaton (2017) found rising rates of pain, in particular sciatic pain and chronic joint pain, across birth cohorts, especially among individuals whose education level is less than a bachelor's degree. In contrast, King et al. (2016) note that rates of chronic lower back pain have remained flat since 1997.

Concurrent with these changes in condition prevalence, there have been increasing rates of functional limitations in the adult population. Iezzoni et al. (2014) used the National Health Interview Survey (NHIS) from 1998 to 2011 and found significant increases in all seven of their constructed measures of chronic disability: movement difficulty, sensory difficulty, emotional difficulty, cognitive difficulty, self-care limitations, social limitations, and work limitations. They find that movement difficulties had the largest increase, from 19\% in 1998 to $23 \%$ in 2011.

Among children, rates of disability have risen substantially both recently and over the last 40 years. Between 2003 and 2011, ADHD rates increased by nearly 4 percentage points, and rates of low birth weight - a risk factor for future disability - increased by nearly five percentage points (Sevak and Bruns 2019). Since 1980, when 3.8\% of children had health-related activity limitations (Newacheck et al. 1986), the rate has risen to $6.9 \%$ in 2001 and $7.9 \%$ in 2011 (Houtrow et al. 2014). ${ }^{3}$ The increase corresponds to a rise in developmental and mental health conditions and is muted by simultaneous decreases in physical disabilities (Houtrow et al. 2014).

Both for children and adults, increases in measured rates of prevalence could partly reflect factors other than true increases in prevalence. For example, improved diagnostic tools could increase accurate diagnoses for conditions such as autism that may previously have been undiagnosed or misdiagnosed. Enhanced access to care, particularly due to the expansion of Medicaid and private health insurance since the Patient Protection and Affordable Care Act in 2010, may mean that part of the documented increase in prevalence reflects increases in diagnoses, holding prevalence constant.

In this study, we build on this literature on prevalence and functioning. We use nationally representative survey data to document trends over the past 21 years in the prevalence of conditions most commonly reported by disability beneficiaries and explore the functional limitations experienced by individuals who report those conditions. We address two research questions: (1) How has the prevalence of certain potentially disabling conditions changed among children and working-age adults over the last two decades? and (2) Among individuals with

\footnotetext{
${ }^{3}$ Estimates vary across studies, depending on the data source and definition of disability.
} 
these conditions, how has the share who report particular functional limitations changed over time? 


\section{DATA}

\section{A. NHIS}

We used data from the National Health Interview Survey (NHIS) from 1997 through 2017. The National Center for Health Statistics at the Centers for Disease Control (CDC) administers this cross-sectional survey annually, collecting information about a range of health-related variables including general health, conditions, symptoms, health coverage, and access to and utilization of medical care among the noninstitutionalized civilian population of the United States. The survey is administered at the household level, with many of the condition variables asked of one adult and child per household. We used data from an IPUMS Health Surveys data extract (Blewett et al. 2018), which harmonizes the data to facilitate multi-year analyses, and we used sample weights in order to produce nationally representative estimates.

\section{B. Sample characteristics}

Our sample contains 509,937 adults (ages 18 to 64) and 252,026 children (ages 0 to 17) about 25,000 adults and 12,500 children per survey year. When weighted, the adult sample has an average age of 40 years, is $51 \%$ female, $80 \%$ white, and $12 \%$ black (Appendix C). Average age in the adult sample increases by two years from 38.8 years in 1997 to 40.9 in 2017, reflecting the aging of the population. The proportion of the sample that is female remains relatively stable over time, and the proportion of the sample that is white decreases over time (from $82.1 \%$ to $76.5 \%$ ), again consistent with demographic changes in the population.

The child sample has an average age of 8.5 years, is $49 \%$ female, $75 \%$ white, and $15 \%$ black. The average age of the child sample remains relatively stable over our study time period, as does the proportion of the sample that is female. The proportion of the sample that is white decreases from 77.1 to $73.2 \%$. 
This page has been left blank for double-sided copying. 


\section{METHODS}

In this section, we describe the four phases of our analysis. First, we identified a list of conditions that are prevalent or growing in the SSI and SSDI beneficiary populations. Second, we mapped those conditions to the conditions recorded in the NHIS to generate population-level estimates of condition prevalence. Third, we constructed measures of functioning in the NHIS. Fourth, we examined trends in condition prevalence and functioning in the U.S. population and subpopulations of people with each of the prevalent conditions, from 1997 through 2017.

\section{A. Identifying prevalent conditions}

We reviewed diagnoses of adult SSDI and SSI and child SSI beneficiaries, as reported in SSA's 2016 Annual Statistical Report (SSA 2016). We grouped conditions into broader diagnostic groups and identified 19 condition groups that were most prevalent among child or adult beneficiaries or whose prevalence has increased substantially since 2006. Appendix A provides more information on these condition groups.

\section{B. Measuring conditions}

We then reviewed an extensive set of NHIS self-reported questions on diagnoses and health experiences to identify variables to measure prevalence of these conditions in the survey samples. We were able to construct measures for the following 16 condition groups: (1) musculoskeletal and connective tissue (adults only), (2) mood disorders (adults only), (3) nervous system and sense organs, (4) circulatory system, (5) intellectual disability (children only), (6) neoplasms (adults only), (7) endocrine, nutritional, and metabolic diseases, (8) respiratory system, (9) genitourinary system (adults only), (10) digestive system (adults only), (11) infectious and parasitic diseases (adults only), (12) blood disorders (children only), (13) skin conditions (children only), (14) autism (children only), (15) congenital anomalies (children only), and (16) developmental disorders (children only). ${ }^{4}$ Appendix Table A1 reports the prevalence of these conditions in the SSDI and child and adult SSI populations, and lists the NHIS items used to construct measures for these conditions.

Even among the diagnostic categories that we could measure in NHIS, some categories are better represented or measured in the NHIS than others. For example, autism, though complex and varied, is clearly identified by a single question asking if a doctor has ever told the parents the child has autism. In contrast, mood disorders are identified from a series of questions on feelings in the last 30 days, which may be more likely to falsely suggest that someone with recent depressive or anxiety symptoms has a mood disorder. Concurrently, these questions may miss identifying someone with a mood disorder who is asymptomatic because the condition was well managed by treatment at the time of the survey. In addition, we recognize that for many conditions, measurement in the NHIS, in other surveys, and even in many diagnostic screens is imperfect and is not always aligned with SSA's definitions for disability determination. Nevertheless, the NHIS provides annual data over 20 years that can shed light on whether population prevalence of these conditions has been changing over time.

\footnotetext{
${ }^{4}$ Although the NHIS has rich information on conditions, we were not able to adequately measure some of the condition groups for children, adults, or both groups, due to small sample size or lack of measures.
} 


\section{Measuring functioning}

After documenting the prevalence trends for the health condition groups, we examined whether functioning among people with conditions changed over time. The NHIS contains many measures of functional limitations; to keep the analysis tractable, we followed the literature (Iezzoni et al. 2014) by grouping the measures into domains of basic action difficulties (BADs) and complex activity limitations (CALs).

We constructed four BADs and five CALs, with some applying to adults but not children and vice versa. The BADs include cognitive limitations, emotional limitations (adults only) movement limitations, and sensory limitations. The CALs include play limitations (children only), self-care limitations, school limitations (children only), social limitations (adults only), and work limitations (adults only). Appendix B provides more detail on the components of the composite measures of functioning for adults and children.

\section{Time trends in conditions and functioning}

After identifying the conditions and functional measures of interest, we estimated time trends in condition prevalence and the share of individuals with a given health condition who report a limitation in each of the functional domains, by year. We used unadjusted trends to estimate the share of individuals with limitations because they illustrate the actual changes over time in the functional limitations experienced among individuals with chronic conditions. However, the unadjusted trends in functioning might also reflect the changing characteristics of the population with a particular condition. To account for the possibility of such changes, we estimated multivariate linear regressions followed by the margins post-estimation command in Stata MP/15.1, to produce regression-adjusted means of each outcome in each year, as well as tests for differences over time. The general form of the equation we used is as follows:

$$
Y=\alpha+\beta(\text { Year } \times(\gamma \text { Age }+\delta \text { Female }+\rho \text { Black }+\omega \text { Other }))+\varepsilon
$$

where $\mathrm{Y}$ is a binary outcome indicating whether the respondent has a condition or a limitation; Year is a vector of years from 1997 through 2017 that is interacted with a vector of covariates including age, an indicator for female gender, an indicator for black race, and an indicator for other races (white is the omitted category). This equation is equivalent to estimating separate regressions for each year, and it allows the coefficient on each covariate to vary by year. We used margins to estimate regression-adjusted proportions in each year, holding constant the characteristics of the 2017 sample to observe changes over time in our outcome, independent of differences in the sample composition. To estimate trends in functioning within populations with selected conditions, we estimated equation 1 on samples restricted to individuals who reported the condition of interest.

We tested for statistically significant trends in two ways. First, we tested for a significant difference in the outcome between 1997 and 2017 using the margins post-estimation command. Second, we estimated linear time trends to test for an increase over the entire 21-year period. Although changes in the prevalence of conditions and reports of limitations may not be monotonic over our 21-year period, the intent of implementing this model is to assess a general trend from 1997 to 2017. 


\section{RESULTS}

In this section, we present selected results of our analyses separately for adults and children. For each group, we first present adjusted trends in condition prevalence and each measure of functioning. We then report trends in selected measures of functioning among the subpopulations of individuals with a particular condition. These measures of functioning are cognitive, social, and sensory limitations for adults and school limitations for children. We highlight the selection of measures with notable trends, rather than all measures of functioning, due to the volume of results.

\section{A. Adults}

The prevalence of several conditions has increased among adults between 1997 and 2017. Figures 1 and 2 present regression-adjusted population time trends in conditions among adults, with conditions with lower prevalence grouped in Figure 1 and those with higher prevalence in Figure 2, for ease of handling scale. Trends in conditions and measures of functioning adjusted for age, race, and gender look similar, but they are slightly muted relative to unadjusted trends. As described in the data section, the sample of adults changes slightly over time and becomes, on average, older and less likely to be white. We would expect to observe higher rates of conditions and limitations among older NHIS respondents, so the changing composition of our sample is likely to bias trends in conditions and limitations upward. Adjusting for age and race mitigates this bias.

Among the eight conditions that we plot, we observe noticeable upward trends in the prevalence of neoplasms (4.3\% in 1997 to $5.4 \%$ in 2017), endocrine disorders (5.6\% in 1997 to $9.4 \%$ in 2017), and obesity (19.8\% in 1997 to $31.2 \%$ in 1997). Circulatory system and mood disorders also appear to have increased ( 24.3 to $26.4 \%$ and 54.6 to $56.2 \%$, respectively) between 1997 and $2017 .{ }^{5}$ We observe very modest decreases in sense organ and nervous system disorders, musculoskeletal disorders, and respiratory disorders.

Next we examine functioning, both in the full population of working-age adults and among the subset that have at least one of the conditions identified in the first step of the analysis (Figure 3). Overall, we find a relatively stable trend in the percentage reporting any limitation roughly $38 \%$ in the full population and $42 \%$ in the subset that have at least one condition. However, underlying the flat trend in aggregate limitations is a declining trend in one measure of functioning and positive trends in others, both in the full population and the subset with one or more condition. Specifically, we find a striking negative trend in the share of adults reporting vision and hearing problems, which declined by a statistically significant 2.6 percentage points from $18.8 \%$ to $16.2 \%$ (Figure 3 ).

\footnotetext{
5 The high estimated prevalence rates for circulatory system and mood disorders reflect the inclusive construction of the variables and NHIS questions. We define both conditions broadly; mood disorders are identified via affirmative response to questions about depression and anxiety symptoms in the weeks prior to the NHIS interview, and circulatory conditions include not just heart attack and congenital conditions but hypertension as well. The mood disorders measure likely misclassifies many people who do not have a clinical mood disorder.
} 


\section{Figure 1. Regression-adjusted trends in neoplasms and endocrine conditions} among adults, 1997-2017

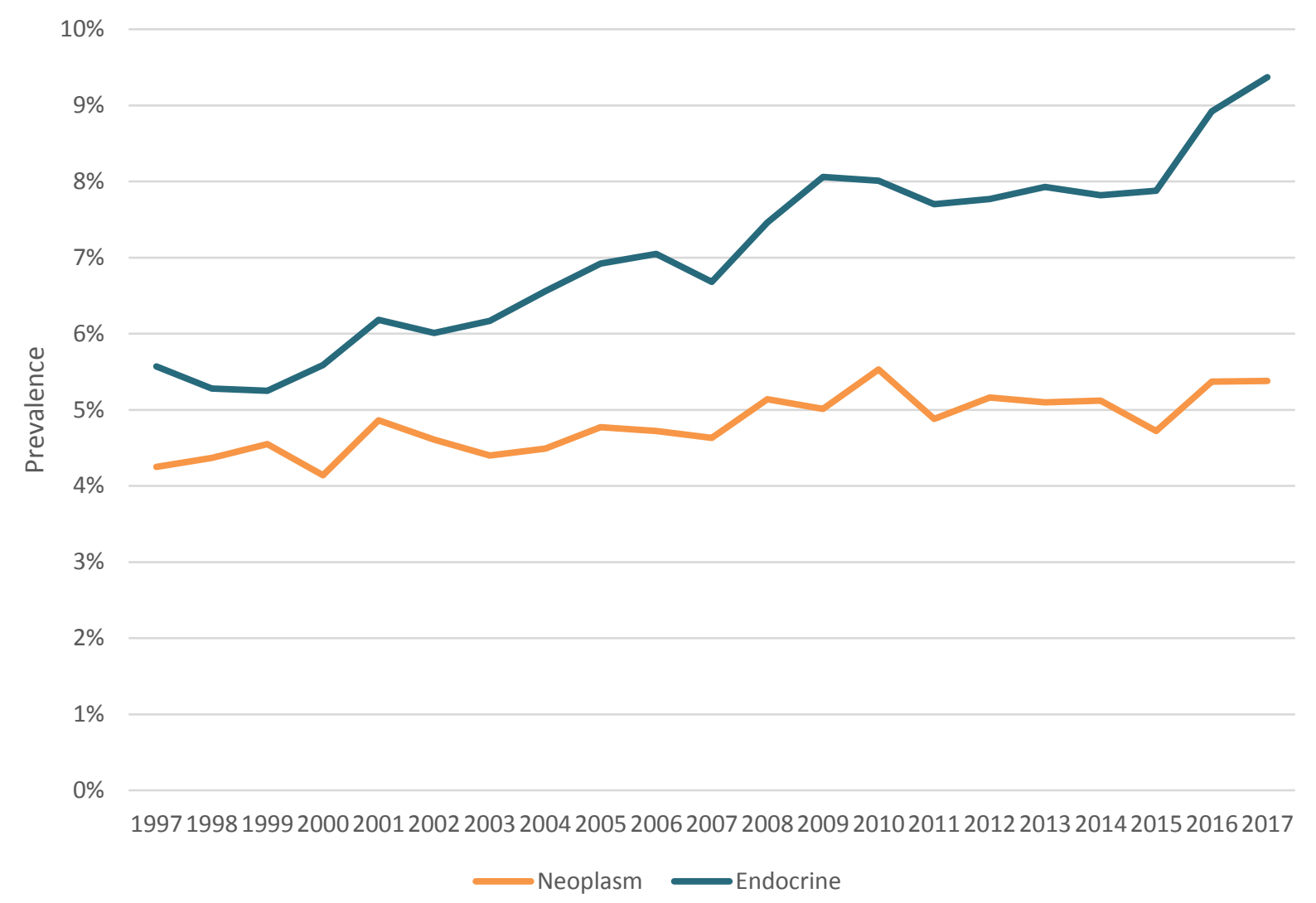

Source: Author's calculation using data from the NHIS Sample Adult file, 1997-2017.

Notes: The time trend is adjusted for age; three race categories including white, black, and other (white is the excluded category); and gender (male is the excluded category). The displayed proportions of NHIS respondents reporting conditions were estimated in Stata MP 15 using linear probability models followed by the margins command to obtain regression-adjusted mean values in each year, holding constant the characteristics of the 2017 sample. 
Figure 2. Regression-adjusted trends in mood conditions, musculoskeletal conditions, sense organ and nervous system conditions, circulatory conditions, respiratory conditions, and obesity, 1997-2017

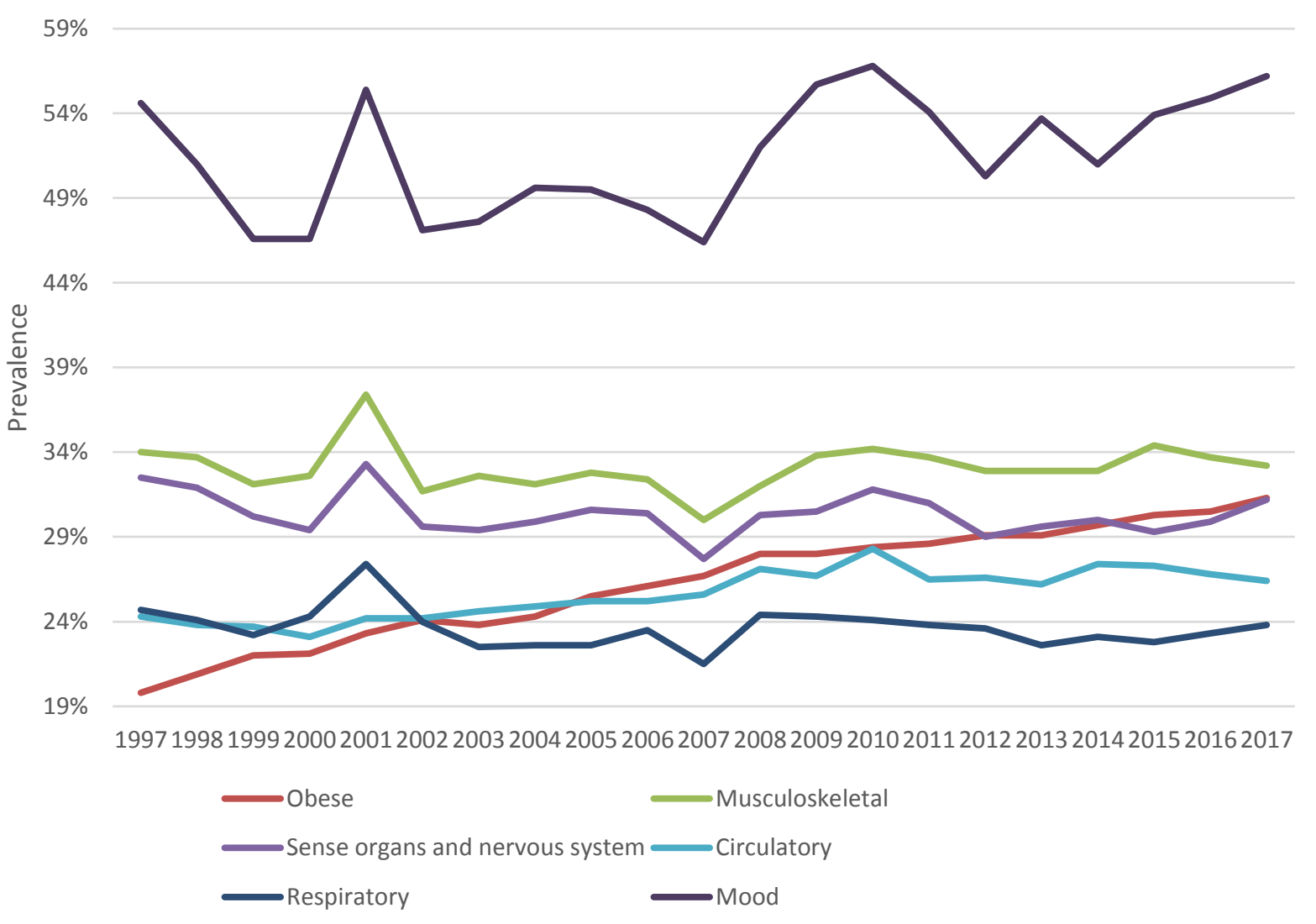

Source: Author's calculation using data from the NHIS Sample Adult file, 1997-2017.

Notes: The time trend is adjusted for age; three race categories including white, black, and other (white is the excluded category); and gender (male is the excluded category). The displayed proportions of NHIS respondents reporting conditions were estimated in Stata MP 15 using linear probability models followed by the margins command to obtain regression-adjusted mean values in each year, holding constant the characteristics of the 2017 sample. 


\section{Figure 3: Regression-adjusted trends in limitations among all adults and adults with at least one medical condition, 1997-2017}

$40 \%$

$$
45 \%
$$
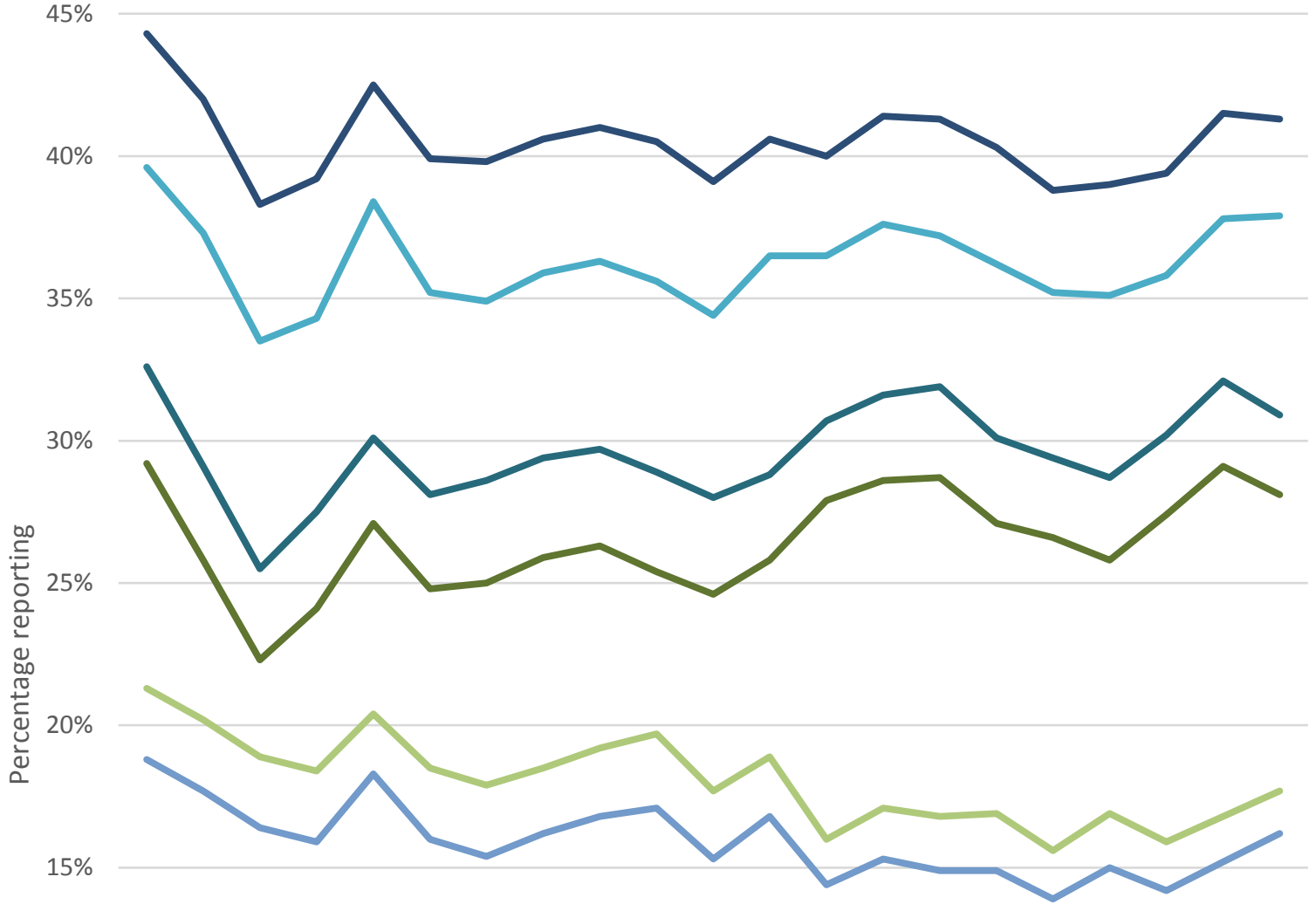

$10 \%$

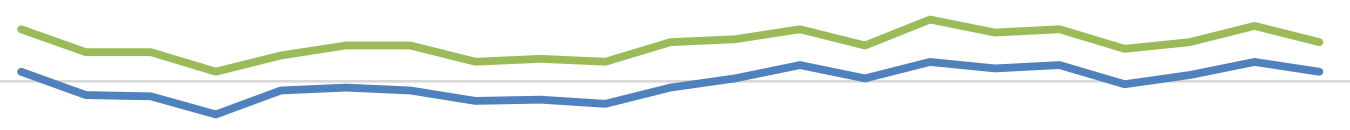

$5 \%$

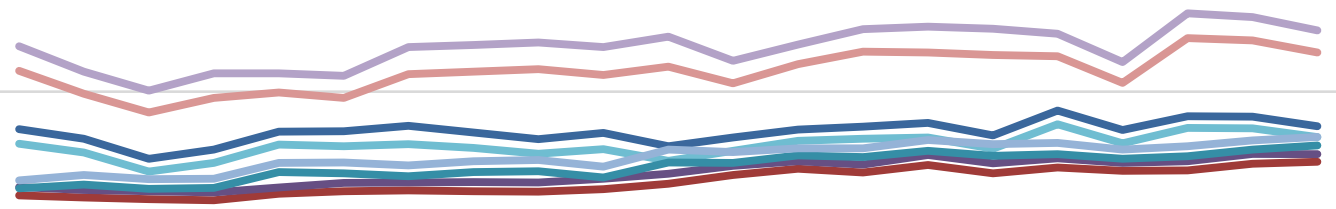

$0 \%$

199719981999200020012002200320042005200620072008200920102011201220132014201520162017

Work Limitation - Population

Work Limitation - Any Condition

Any Limitation - Population

-Any Limitation - Any Condition

BAD Movement - Population

BAD Sense - Population

BAD Emotional - Population

BAD Movement - Any Condition

BAD Sense - Any Condition

BAD Cognitive - Population

BAD Emotional - Any condition

BAD Cognitive - Any Condition

Source: Author's calculation using data from the NHIS Sample Adult file, 1997-2017.

Notes: The time trend is adjusted for age; three race categories including white, black, and other (white is the excluded category); and gender (male is the excluded category). The displayed proportions of NHIS respondents reporting conditions were estimated in Stata MP 15 using linear probability models followed by the margins command to obtain regression-adjusted mean values in each year, holding constant the characteristics of the 2017 sample. 
Among the limitations with positive trends, the most noticeable increase is in reports of movement limitations - roughly $25 \%$ in most years early in the study period but approaching $30 \%$ in more recent years. Although the difference between 1997 and 2017 is not statistically significant, the linear time trend is positive and significant for the full population and the subset with one or more conditions. Reports of work limitations also increased, though only slightly from year to year, with an average annual increase of 0.03 percentage points. We also observe notable increases in the share of adults that is experiencing cognitive limitations, social limitations, and emotional limitations. These are harder to see in Figure 3 because they are rarer, but we find statistically significant increases over time. Although limitations are universally more prevalent among adults with one or more self-reported conditions, we do not find that the trends over time among adults with medical conditions have differed from those in the full population.

To examine functioning in more detail among individuals with particular conditions, we next examine regression-adjusted time trends in selected functional limitations among individuals with any medical condition (shown in Figure 3) as well as among the separate subsets with obesity, musculoskeletal conditions, endocrine conditions, sense organ and nervous system conditions, and symptoms of a mood disorder.

Figure 4 shows that the observed population-level decline in hearing and vision limitations (Figure 3) is more pronounced among individuals with obesity, conditions of the nervous system and sense organs, circulatory conditions, neoplasms, mood disorders, and endocrine conditions.

Figure 5 shows trends in BADs due to cognitive limitations. In the full adult population, BADs due to cognitive limitations have increased from $1.8 \%$ in 1997 to $2.9 \%$ in 2017. This difference is statistically significant, as is the linear time trend. Rates of BADs due to cognitive limitations are higher among adults with medical conditions (relative to all adults) in all years between 1997 and 2017, but the trend in the prevalence of limitations is similar to the trend in the overall population among all groups of people with medical conditions.

Figure 6 plots the trends in social limitations from 1997 to 2017. Reporting of social limitations in the overall population increased modestly from 1997 to 2017 , from $5.6 \%$ to $6.2 \%$. Reporting of social limitations is higher among adults with conditions in all years between 1997 and 2017, and the time trend among this group is similar to the trend in the overall population, with two exceptions. Among individuals with musculoskeletal conditions or nervous system and sense organ conditions, the increases in social limitations are noticeably more pronounced.

\section{B. Children}

Next, we examine trends in conditions and functioning among children. Generally, we find that the prevalence of several conditions has increased among children between 1997 and 2017, most notably respiratory, skin, developmental, and intellectual conditions. We find slight increases in school limitations and slight decreases in limitations due to hearing or vision problems. Similar to the results for adults, limitations are universally more prevalent among children with self-reported medical conditions, and we do not find statistically significant trends in limitations among children with medical conditions. However, our results suggest that trends within these groups might be more pronounced. 


\section{Figure 4. Regression-adjusted trends in functional limitation due to hearing} and vision problems among all adults and adults with conditions, 1997-2017

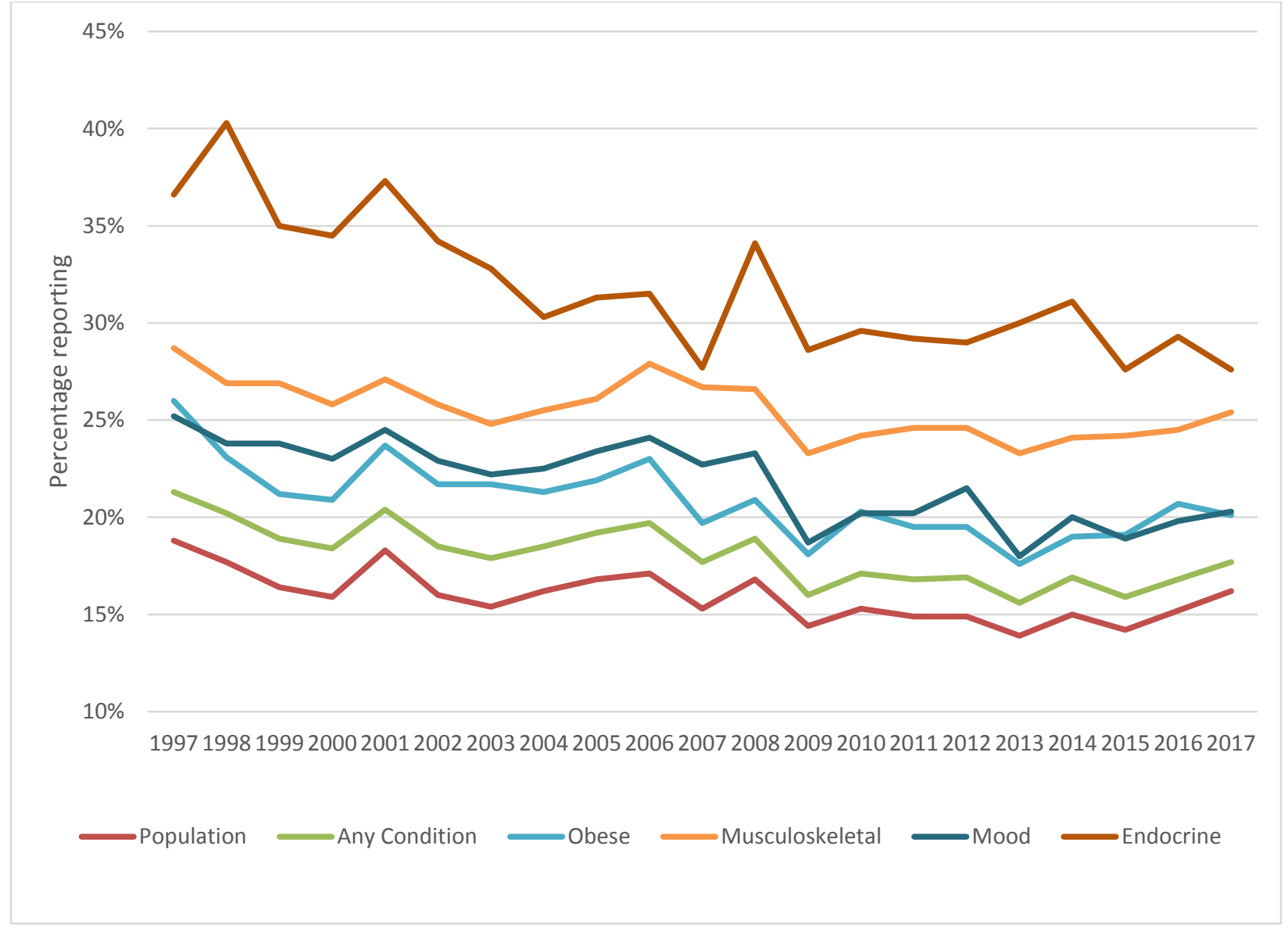

Source: Author's calculation using data from the NHIS Sample Adult file, 1997-2017.

Notes: The time trend is adjusted for age; three race categories including white, black, and other (white is the excluded category); and gender (male is the excluded category). The displayed proportions of NHIS respondents reporting conditions were estimated in Stata MP 15 using linear probability models followed by the margins command to obtain regression-adjusted mean values in each year, holding constant the characteristics of the 2017 sample. 
Figure 5. Regression-adjusted trends in basic action difficulties due to cognitive limitations among all adults and adults with conditions, 1997-2017

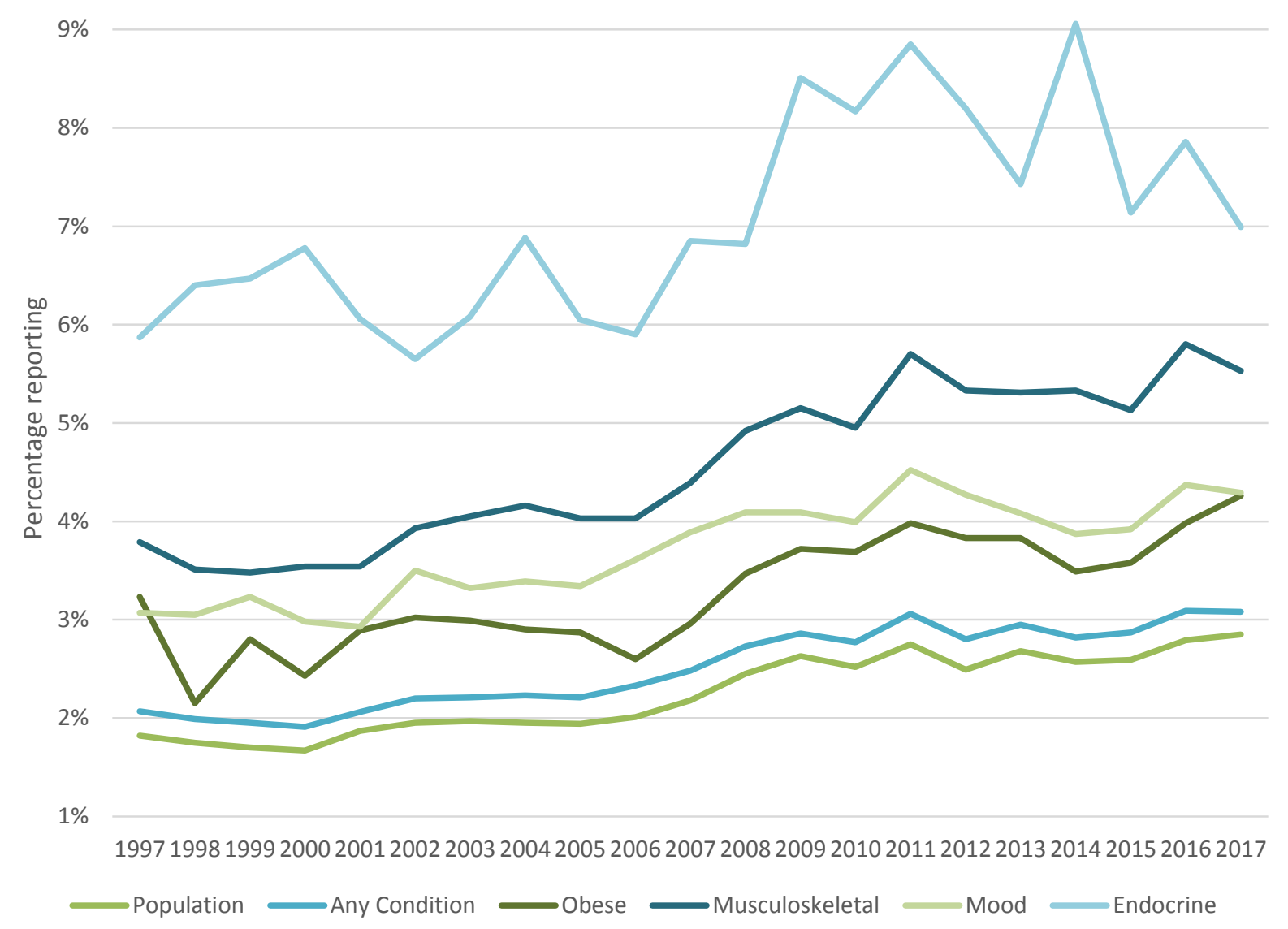

Source: Author's calculation using data from the NHIS Sample Adult file, 1997-2017.

Notes: The time trend is adjusted for age; three race categories including white, black, and other (white is the excluded category); and gender (male is the excluded category). The displayed proportions of NHIS respondents reporting conditions were estimated in Stata MP 15 using linear probability models followed by the margins command to obtain regression-adjusted mean values in each year, holding constant the characteristics of the 2017 sample. 


\section{Figure 6. Regression-adjusted trends in social limitation among all adults and adults with conditions, 1997-2017}

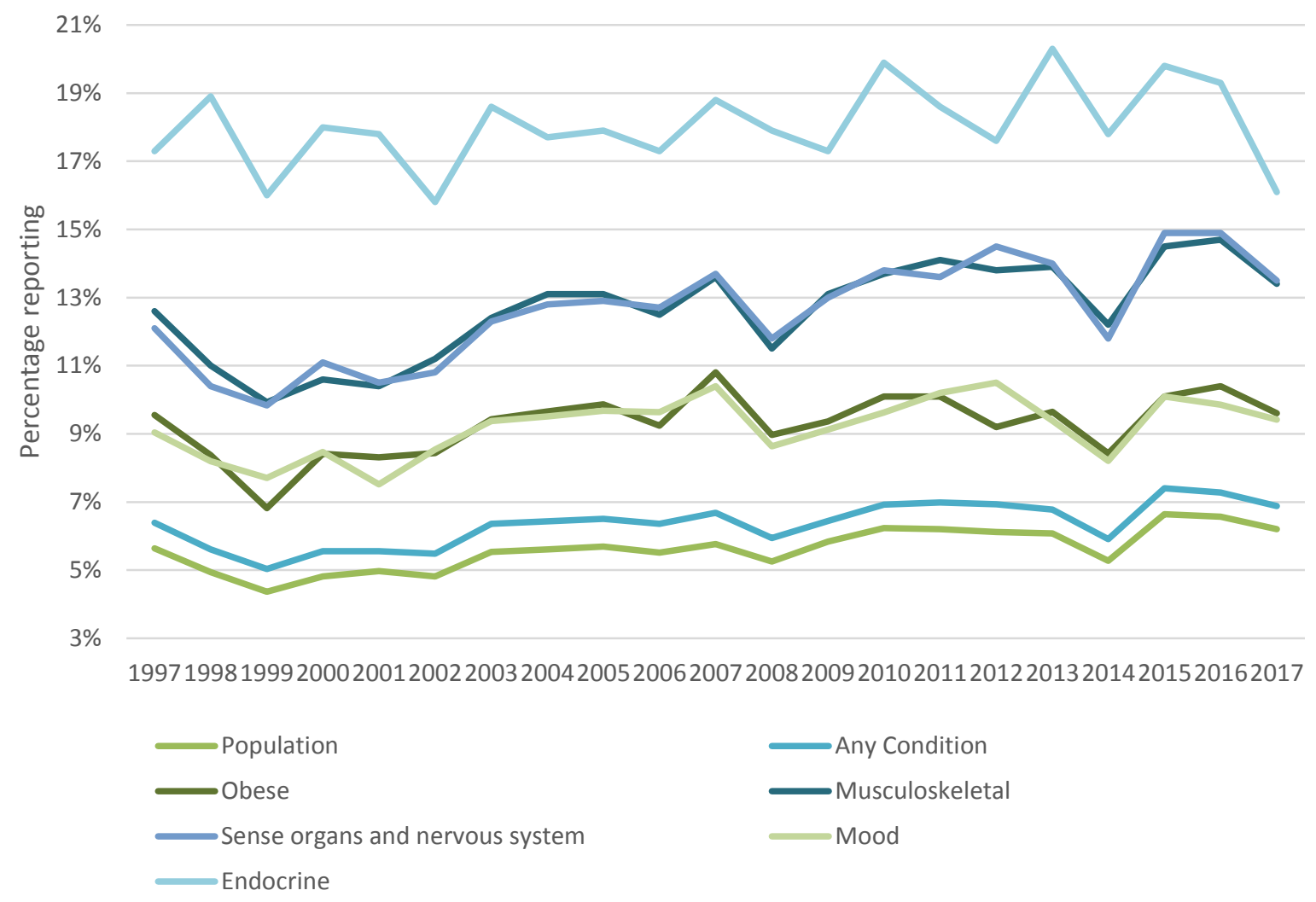

Source: Author's calculation using data from the NHIS Sample Adult file, 1997-2017.

Notes: The time trend is adjusted for age; three race categories including white, black, and other (white is the excluded category); and gender (male is the excluded category). The displayed proportions of NHIS respondents reporting conditions were estimated in Stata MP 15 using linear probability models followed by the margins command to obtain regression-adjusted mean values in each year, holding constant the characteristics of the 2017 sample.

We present regression-adjusted trends in self-reported medical conditions among children, again grouped into two figures based on higher-prevalence conditions (Figure 7) and lowerprevalence conditions (Figure 8) for ease of scale. Among the more prevalent conditions, there are observable increases in the prevalence of respiratory (11.4 to $13.0 \%$ ), skin (8.0 to $13.5 \%$ ), and developmental conditions ( 9.5 to $13.7 \%$ ), but a slight decrease in the prevalence of sense organ and nervous system disorders. Among the less prevalent conditions, there is a dramatic increase in the prevalence of autism between 1997 and $2017^{6}$ - though prevalence is still low at $2.12 \%$ - and a small increase in intellectual conditions $(0.5$ to $0.9 \%)$. There is a slight decrease in the prevalence of circulatory conditions and those concerning blood and blood-forming organs. The prevalence of congenital disorders was relatively stable between 1997 and 2017.

\footnotetext{
${ }^{6}$ The wording of the NHIS question about autism was revised in 2014 from "Autism/Autism spectrum disorder" to "Autism, Asperger's disorder, pervasive developmental disorder, or autism spectrum disorder," which is likely a contributing factor to the spike in autism prevalence that we observe in 2014.
} 
Figure 7. Regression-adjusted trends in sense organ and nervous system, skin, respiratory, and developmental conditions among children, 1997-2017

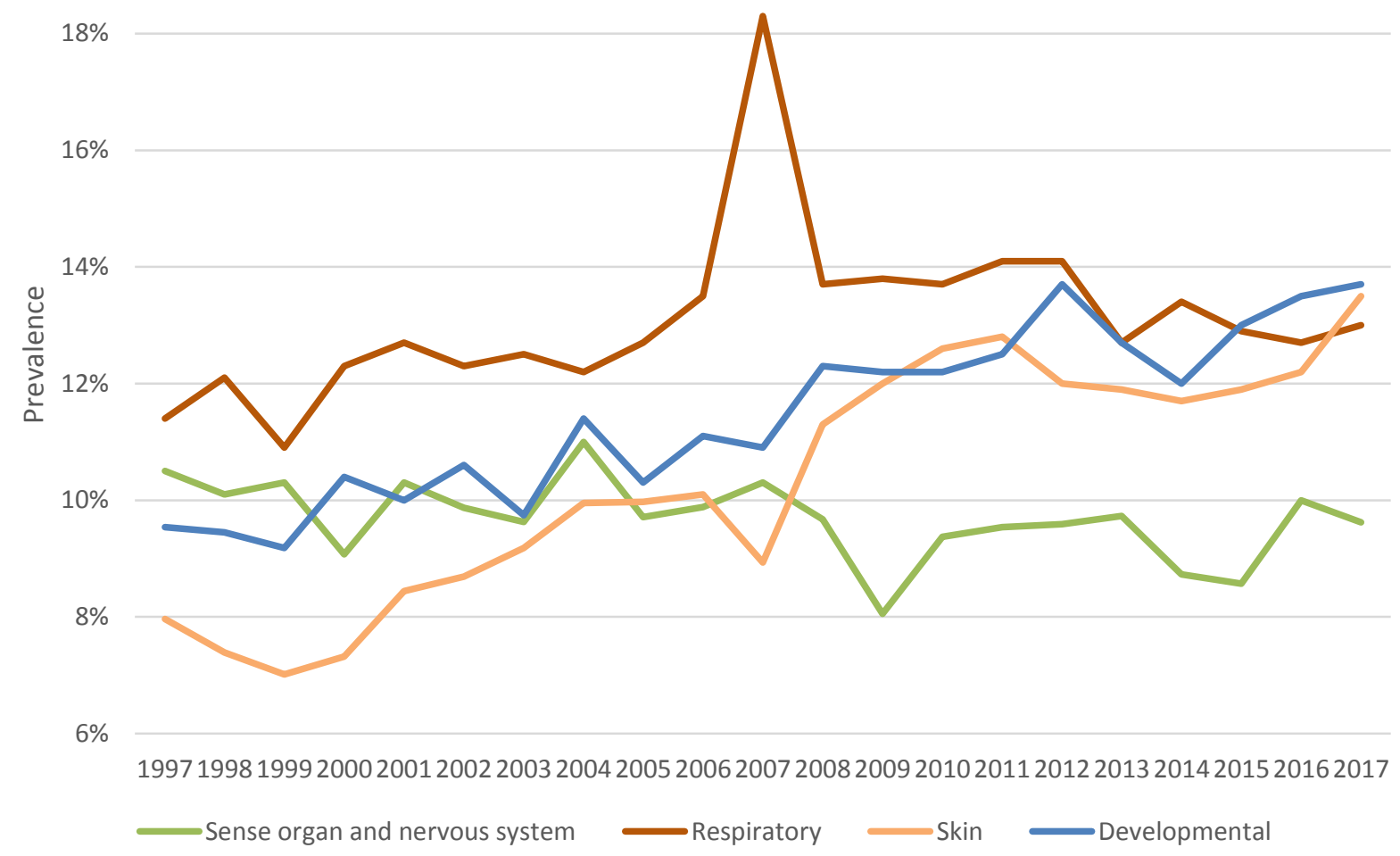

Source: Author's calculation using data from the NHIS Sample Child file, 1997-2017.

Notes: The time trend is adjusted for age; three race categories including white, black, and other (white is the excluded category); and gender (male is the excluded category). The displayed proportions of NHIS respondents reporting conditions were estimated in Stata MP 15 using logistic regression followed by the margins command to obtain regression-adjusted mean values in each year, holding constant the characteristics of the 2017 sample. 


\section{Figure 8. Regression-adjusted trends in circulatory conditions, blood and blood-forming organ conditions, congenital conditions, intellectual conditions, and autism among children, 1997-2017}

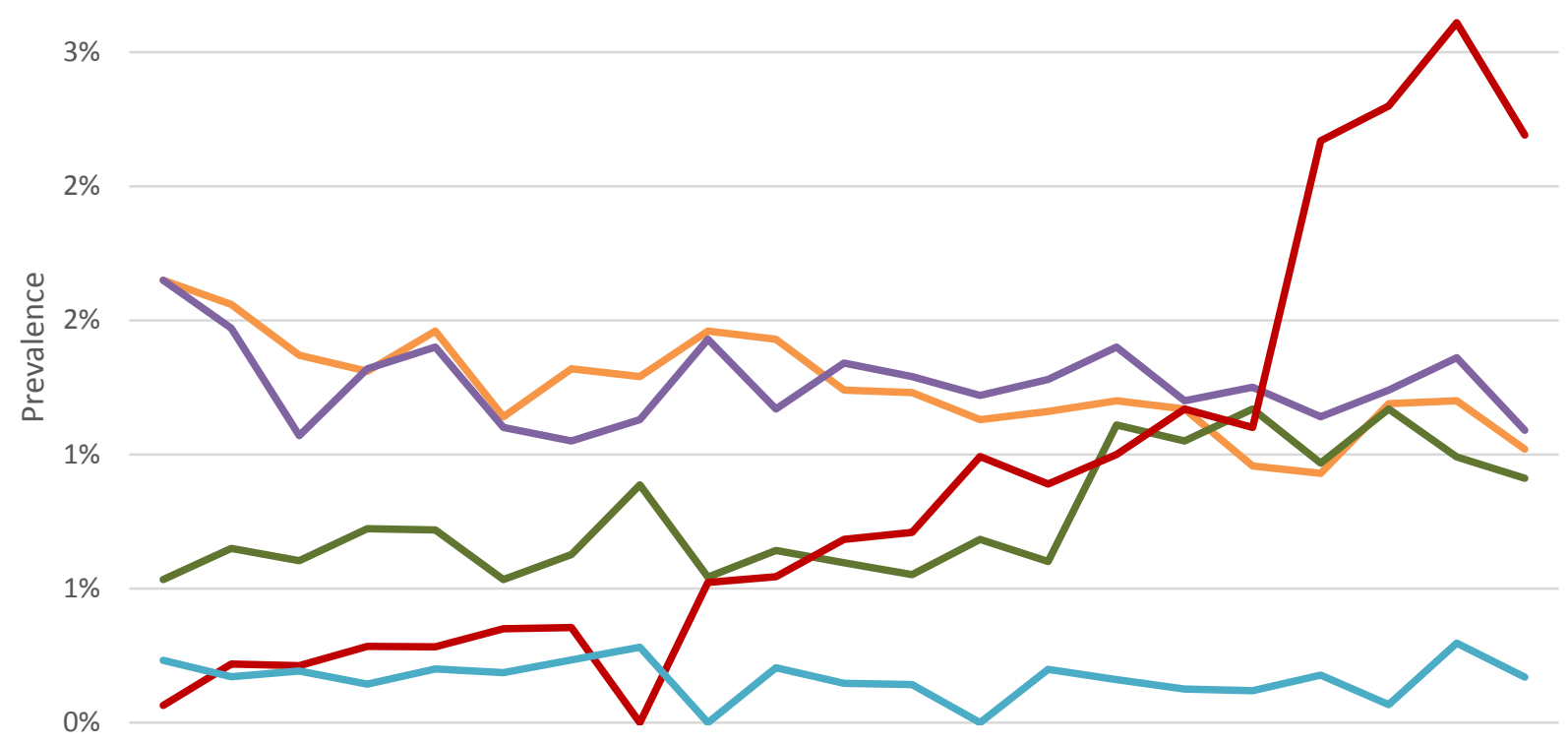

199719981999200020012002200320042005200620072008200920102011201220132014201520162017

Circulatory Intellectual $\longrightarrow$ Blood and blood-forming organs $\longrightarrow$ Autism Congenital

Source: Author's calculation using data from the NHIS Sample Child file, 1997-2017.

Notes: The time trend is adjusted for age; three race categories including white, black, and other (white is the excluded category); and gender (male is the excluded category). The displayed proportions of NHIS respondents reporting conditions were estimated in Stata MP 15 using logistic regression followed by the margins command to obtain regression-adjusted mean values in each year, holding constant the characteristics of the 2017 sample. Note that the wording of the autism survey question was revised for the 2014 version.

Figure 9 presents trends in all six measures of limitations in the U.S. population of children under age 18, as well as among children with at least one condition. Limitations are generally rare among children; most limitations are reported in less than $5 \%$ of the overall population of children. School limitations are the most common, and they range from a minimum of $5.5 \%$ in 1997 to a maximum of $8.9 \%$ in 2017 . The range of the composite measure of any limitation is $9.2 \%$ to $13.1 \%$ among the overall population of children. Of the six measures of limitations we use for this study and the seventh composite measure of any limitation, only three change by more than 1 percentage point between 1997 and 2017. We find minimal changes in the prevalence of BADs due to cognitive limitations, movement limitations, self-care limitations, and play limitations. 


\section{Figure 9. Regression-adjusted trends in limitations among all children and children with at least one medical condition, 1997-2017}

$30 \%$

$25 \%$
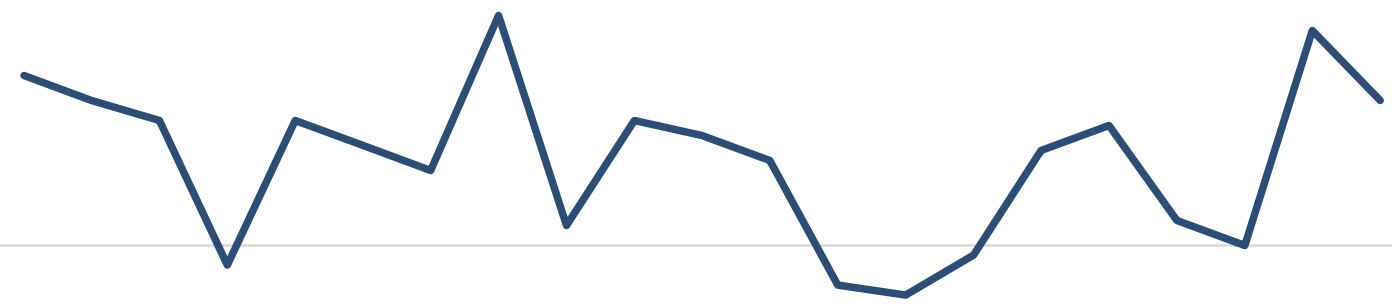

$20 \%$

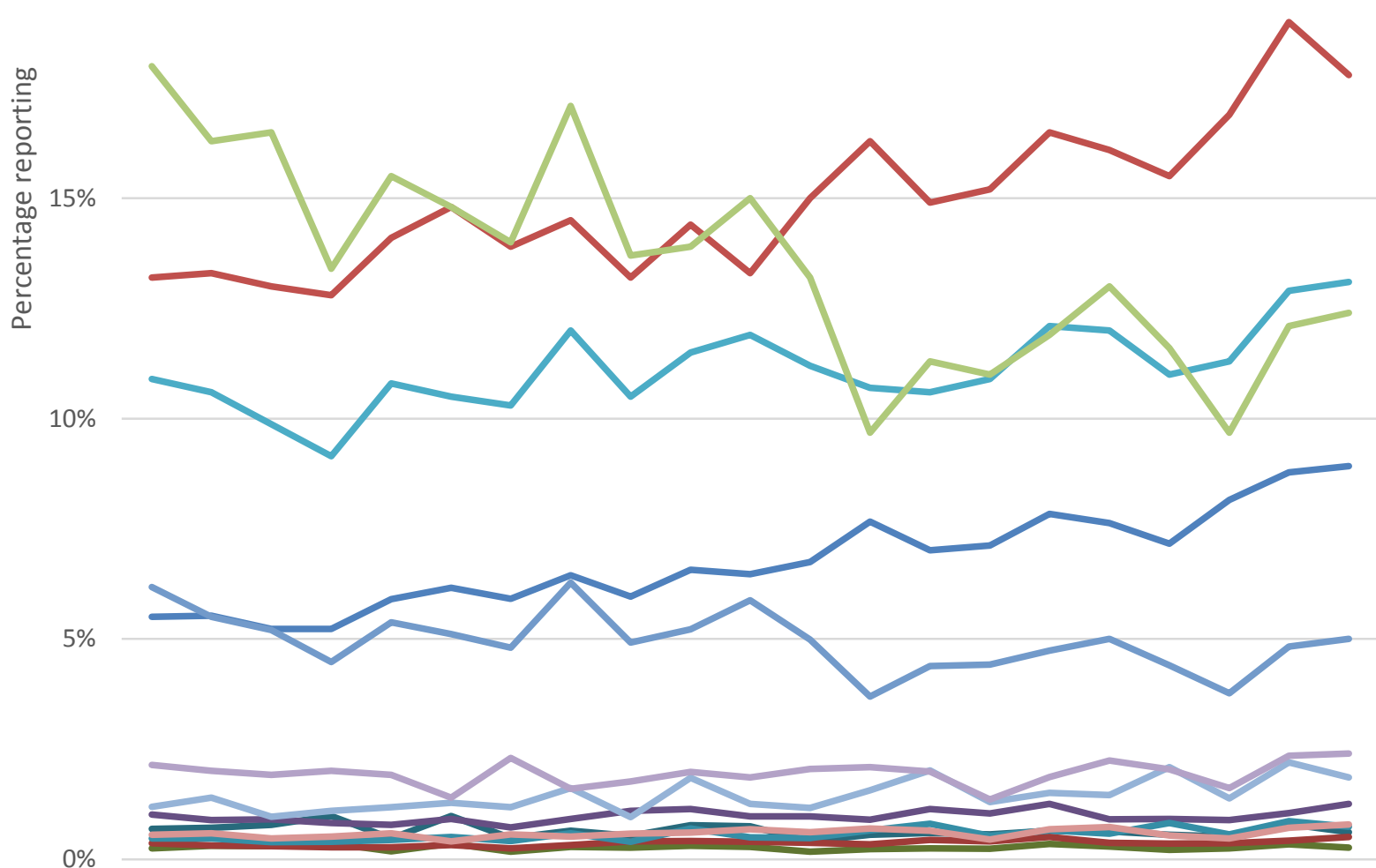

$0 \%$

199719981999200020012002200320042005200620072008200920102011201220132014201520162017

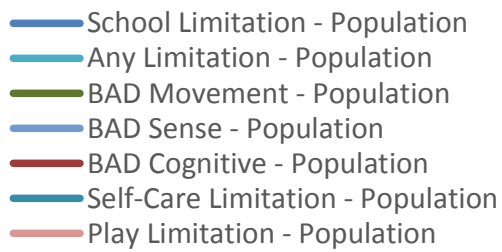

School Limitation - Any Condition

- Any Limitation - Any Condition

BAD Movement - Any Condition

BAD Sense - Any Condition

BAD Cognitive - Any Condition

Self-Care Limitation - Any Condition

Play- Any Condition

Source: Author's calculation using data from the NHIS Sample Child file, 1997-2017.

Notes: Time trends are adjusted for age; three race categories including white, black, and other (white is the excluded category); and gender (male is the excluded category). The displayed proportions of NHIS respondents reporting conditions were estimated in Stata MP 15 using logistic regressions followed by the margins command to obtain regression-adjusted mean values in each year, holding constant the characteristics of the 2017 sample. 
Reporting of any of the six limitations increased slightly (by 2.2 percentage points) between 1997 and 2017. The linear time trend is positive and significant for the whole population of children and children with medical conditions. The prevalence of limitations due to vision and hearing problems among all children decreased from 6.2 to 5.0\% between 1997 and 2017 .

Figure 10 presents trends in school limitations from 1997 to 2017 in the overall population and among children with selected medical conditions. The overall population prevalence of school limitations increased from 5.5\% in 1997 to $8.9 \%$ in 2017. The linear time trend test indicates that the increase is statistically significant. The prevalence of school limitations was higher among children with medical conditions than the overall population prevalence in all years, and the trend was more dramatic among children in all of the condition groupings, though the coefficient on the linear time trend is not statistically significant for any condition group.

\section{Figure 10. Regression-adjusted trends in school limitation among all children and children with at least one medical condition, 1997-2017}

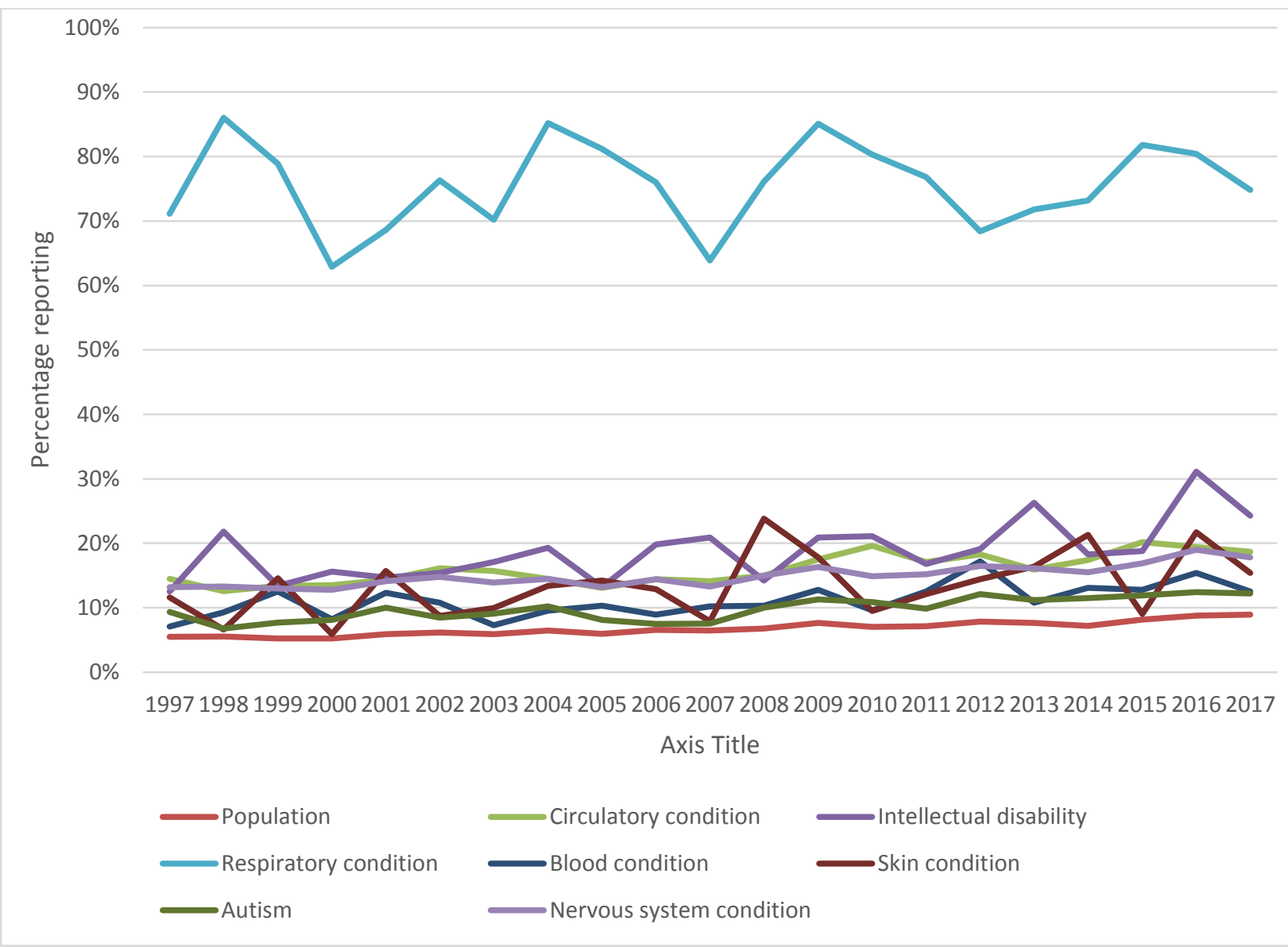

Source: Author's calculation using data from the NHIS Sample Child file, 1997-2017.

Notes: Time trends are adjusted for age; three race categories including white, black, and other (white is the excluded category); and gender (male is the excluded category). The displayed proportions of NHIS respondents reporting conditions were estimated in Stata MP 15 using logistic regressions followed by the margins command to obtain regression-adjusted mean values in each year, holding constant the characteristics of the 2017 sample. 


\section{DISCUSSION}

In this paper, we used nationally representative survey data from the NHIS to document adjusted trends over the past 20 years in chronic conditions and functioning. Our motivation to examine these trends has been to show how the growth and changing composition of SSA disability beneficiaries can be explained by changes in population prevalence and functioning, beyond changes that are just due to population aging and other demographic shifts. Although our study is limited by the measures in the NHIS (which do not perfectly measure prevalence of all chronic conditions), the data provide relatively consistent measures of conditions and functioning over many years. Overall, we find changes in the population that are consistent with some but not all of the changes observed among SSA beneficiaries.

Among adults we find that, whereas the share reporting one or more chronic conditions has remained relatively stable in aggregate, the prevalence of specific conditions is changing, with some conditions increasing in prevalence, some declining, and others remaining stable. The increases in obesity and endocrine conditions (diabetes) in the NHIS are consistent, with welldocumented trends and public health concerns and increasing rates of obesity among beneficiaries (Schimmel Hyde 2016). However, we observe only a modest increase in mood disorders and a slight declining trend in musculoskeletal disorders, despite the fact that individuals with musculoskeletal and psychiatric disabilities make up an increasing share of beneficiaries (National Academies of Sciences, Engineering, and Medicine, 2015).

The absence of large positive trends in musculoskeletal and mood disorders may be reconciled with their increasing share among SSA beneficiaries by our finding of several measures of worsening function for this population. Among individuals with musculoskeletal or mood disorders, we observe marked increases in mobility, memory, and social limitations. It could be that the number of beneficiaries with these conditions has risen dramatically not because of increases in prevalence but because of declines in functioning among people who have these conditions.

Although the time trend in reporting any functional limitation was relatively flat, worsening function in a number of domains raises additional questions. First, the increases in cognitive and social limitations in the full population, with or without conditions, are concerning and consistent with reports in the popular press that Americans are increasingly socially isolated (Khullar 2016). Furthermore, that individuals with chronic conditions that seemingly have nothing to do with memory have significantly higher rates of cognitive limitations is concerning and suggests the impact of these conditions over time may extend beyond the physical symptoms that are associated with them. Similarly, that individuals with chronic conditions have higher rates of social limitations is unfortunate and illustrates that chronic conditions and disability can contribute to social isolation, which may further exacerbate the impact of the disability on a person's other domains of functioning.

Among children, we find increases in a number of conditions. The most dramatic trend is the more than quadrupling of the rate of autism, from less than $0.5 \%$ of children in the late 1990 s to more than $2 \%$ of children in recent years. Although the spike in the rate in 2014 is likely to reflect changes in the wording of the autism condition question in the survey, the overall positive trend is also likely to result partly from improved awareness and increased testing and diagnosis 
of autism spectrum disorders (Hansen et al. 2015; King and Bearman 2009). Despite this increase, autism is rare among children relative to developmental disabilities, which also increased substantially. These increases are consistent with SSA data on recent allowances that show that the three most prevalent primary impairments among children allowed for SSI were for attention deficit disorder (ADD) or ADHD, speech and language delay, and autistic disorder and other pervasive development disorders (U.S. GAO 2012). In our study, ADD, ADHD, and speech and language delays are all grouped into a single category: developmental disabilities.

These increases in population prevalence are consistent with the growth in child SSI caseloads. In addition, the relatively flat trends in functioning for children suggest that despite these large increases in condition prevalence, caseload growth may not be as steep because of stable rates in most measures of functioning. The one exception is the increase in reporting of school limitations. This increase, like the increase in the prevalence of autism, could have been partly caused by an increase in the diagnosis of learning disabilities and conditions such as autism, as well as an increase in the availability of supports at school. The mostly flat trends in functioning are also consistent with some findings on child SSI applications versus allowances. For example, whereas child SSI applications for ADHD have increased more than for any other conditions, most ADHD applicants were denied because they did not meet the medical criteria for SSI (U.S. GAO 2012).

In sum, our results suggest that some share of the changing composition of conditions among SSA beneficiaries can be explained by changes in the prevalence of conditions in the population. This is particularly true among children, where the increase in caseloads is driven by an increase in prevalence of select conditions, including autism, developmental disorders such as ADHD, and speech and language delays. However, among adults, the relatively flat prevalence of some conditions such as musculoskeletal and mood disorders suggests that the large increases in the share of beneficiaries with those conditions could reflect declines in social functioning, cognition, and mobility. Increases in opioid abuse could also be a factor, though it was not investigated in this study. The increases could also correspond to changes in program rules or other policy or labor market factors that have been documented in the literature. Nevertheless, our results suggest that initiatives to improve physical and social functioning among individuals with chronic conditions may be warranted, particularly if, as the literature suggests, increased social capital is associated with better health and employment outcomes (Brucker 2015). 


\section{REFERENCES}

Alley, Dawn E., Virginia W. Chang, and Jalpa A. Doshi. "The Shape of Things to Come: Obesity, Aging, and Disability.” LDI Issue Brief, vol. 13, no. 3, 2008, pp. 1-4.

Anand, Priyanka, and Yonatan Ben-Shalom. "The Promise of Better Economic Outcomes for Workers with Musculoskeletal Conditions.” New York: Hunter College, Roosevelt House Faculty Forum, May 2017. Available at: http://www.roosevelthouse.hunter.cuny.edu/?forum-post=promise-better-economicoutcomes-workers-musculoskeletal-conditions.

Autor, David H., and Mark G. Duggan. "The Growth in the Social Security Disability Rolls: A Fiscal Crisis Unfolding." Journal of Economic Perspectives, vol. 20, no. 3, 2006, pp. 71-96.

Blewett, Lynn A., Julia A. Rivera Drew, Risa Griffin, Miriam L. King, and Kari C.W. Williams. "IPUMS Health Surveys: National Health Interview Survey, Version 6.3 [dataset]." Minneapolis, MN: IPUMS, 2018. http://doi.org/10.18128/D070.V6.3.

Brucker, Debra L. "Social Capital, Employment and Labor Force Participation Among Persons with Disabilities.” Journal of Vocational Rehabilitation, vol. 43, no. 1, 2015, pp. 17-31.

Case, Anne, and Angus Deaton. "Mortality and Morbidity in the 21st Century." Brookings Papers on Economic Activity, 2017, pp. 397-476.

Center for Budget and Policy Priorities. "Chart Book: Social Security Disability Insurance." Washington, DC: Center for Budget and Policy Priorities, 2018. Available at: https://www.cbpp.org/research/social-security/chart-book-social-security-disabilityinsurance. Accessed March 15, 2019.

Deshpande, Manasi, and Yue Li. "Who Is Screened Out? Application Costs and the Targeting of Disability Programs." Cambridge, MA: National Bureau of Economic Research, 2017. Available at: https://www.nber.org/papers/w23472.

Hansen, Stefan N., Diana E. Schendel, and Erik T. Parner. "Explaining the Increase in the Prevalence of Autism Spectrum Disorders: The Proportion Attributable to Changes in Reporting Practices.” JAMA Pediatrics, vol. 169, no. 1, 2015, pp. 56-62. doi:10.1001/jamapediatrics.2014.1893.

Houtrow, Amy J., Kandyce Larson, Lynn M. Olson, Paul W. Newacheck, and Neal Halfon. “Changing Trends of Childhood Disability, 2001-2011." Pediatrics, vol. 134, no. 3, 2014, pp. 530-538.

Iezzoni, Lisa, Stephen G. Kurtz, and Sowmya R. Rao. "Trends in U.S. Adult Chronic Disability Rates Over Time.” Disability and Health Journal, vol. 7, no. 4, 2014, pp. 402-412.

Khullar, Dhruv. "How Social Isolation Is Killing Us." New York Times, The Upshot, December 22, 2016. Available at: https://www.nytimes.com/2016/12/22/upshot/how-social-isolationis-killing-us.html). Accessed March 8, 2019. 
King, Marissa, and Peter Bearman. "Diagnostic Change and the Increased Prevalence of Autism.” International Journal of Epidemiology, vol. 38, no. 5, 2009, pp. 1224-1234.

King, Nicholas B., Erin Strumpf, and Sam Harper. "Has the Increase in Disability Insurance Participation Contributed to Increased Opioid-Related Mortality?" Annals of Internal Medicine, August 2016.

Kochanek, Kenneth D., Elizabeth Arias, and Brigham A. Bastian. "The Effect of Changes in Selected Age-Specific Causes of Death on Non-Hispanic White Life Expectancy Between 2000 and 2014." Data Brief no. 250. Hyattsville, MD: National Center for Health Statistics, 2016.

Liebman, Jeffrey B. "Understanding the Increase in Disability Insurance Benefit Receipt in the United States.” Journal of Economic Perspectives, vol. 29, no. 2, 2015, pp. 123-150.

Manchester, Joyce, and Jae Song. "What Can We Learn from Analyzing Historical Data on Social Security Entitlements?” Social Security Bulletin, vol. 71, no. 4, 2011, pp. 1-13.

Menke, Andy, Sara Casagrande, Linda Geiss, and Catherine Cowie. "Prevalence of and Trends in Diabetes Among Adults in the United States, 1988-2012." Journal of the American Medical Association, vol. 314, no. 10, 2015, pp.1021-1029. doi:10.1001/jama.2015.10029.

National Academies of Sciences, Engineering, and Medicine. Mental Disorders and Disabilities Among Low-Income Children. Washington, DC: National Academies Press, 2015.

Newacheck, Paul W., Neal Halfon, and Peter P. Budetti. "Prevalence of Activity Limiting Chronic Conditions Among Children Based on Household Interviews." Journal of Chronic Diseases, vol. 39, no. 2, 1986, pp. 63-71.

Nichols, Austin, Lucie Schmidt, and Purvi Sevak. "Economic Conditions and SSI Applications." Social Security Bulletin, vol. 77, no. 4, 2017, pp. 27-44.

Pattison, David, and Hilary Waldron. "Growth in New Disabled-Worker Entitlements, 1970 2008.” Social Security Bulletin, vol. 73, no. 4, 2013, pp. 25-48.

Reno, Virginia P. "Securing the Future of the Social Security Disability Insurance Program." Testimony before the House Committee on Ways and Means, Subcommittee on Social Security. December 2, 2011. http://www.nasi.org/research/2011/testimony-virginia-p-renosecuring-future-social-security-di.

Rupp, Kalman. "Factors Affecting Initial Disability Allowance Rates for the Disability Insurance and Supplemental Security Income Programs: The Role of the Demographic and Diagnostic Composition of Applicants and Local Labor Market Conditions." Social Security Bulletin, vol. 72, no. 4, 2012, pp. 11-35. 
Schimmel Hyde, Jody. "The Prevalence of Obesity Among Recent Applicants to Federal Disability Programs." Disability Research Consortium Brief. Washington, DC: Mathematica Policy Research, 2016.

Schmidt, Lucie, and Purvi Sevak. "Child Participation in Supplemental Security Income: Crossand Within-State Determinants of Caseload Growth.” Journal of Disability Policy Studies, vol. 28, no. 3, 2017, pp. 131-140.

Schwartz, Nelson D. "Disability Applications Plunge as the Economy Strengthens." New York Times, Wednesday, June 20, 2018. Available at https://www.nytimes.com/2018/06/19/business/economy/social-security-applications.html. Accessed March 15, 2019.

Sevak, Purvi and Steven Bruns. "What Have We Learned About SSI Receipt Among Children?" Disability Research Consortium Brief. Washington, DC: Mathematica Policy Research, 2019.

Sevak, Purvi, and Shamima Khan. "Psychiatric vs. Physical Disabilities: A Comparison of Barriers and Facilitators to Employment." Psychiatric Rehabilitation Journal, vol. 40, no. 2, 2017, pp. 163-171.

Social Security Administration. "Trends in the Social Security and Supplemental Security Income Disability Programs.” Washington, DC: SSA, 2016. Available at: https://www.ssa.gov/policy/docs/chartbooks/disability trends/. Accessed on December 11, 2017.

Sturm, Roland, Jeanne S. Ringel, and Tatiana Andreyeva. "Increasing Obesity Rates and Disability Trends. Health Affairs, vol. 23, no. 2, 2004, pp. 199-205.

U.S. Government Accountability Office. Supplemental Security Income: Better Management Oversight Needed for Children's Benefits. (GAO-14-497). Washington, DC: GAO, 2012.

Viester, Laura, Evert A. Verhagen, Karen M. O. Hengel, Lando L. Koppes, Aallard J. van der Beek, and Paulien M. Bongers. "The Relation Between Body Mass Index and Musculoskeletal Symptoms in the Working Population." BMC Musculoskeletal Disorders, vol. 14, no. 238, 2013.

Watanabe-Galloway, Shinobu, and Wanqing Zhang. "Analysis of U.S. Trends in Discharges from General Hospitals for Episodes of Serious Mental Illness, 1995-2002." Psychiatric Services, vol. 58, no. 4, 2007, pp. 496-502. 
This page has been left blank for double-sided copying. 
APPENDIX A

SSA TO NHIS CONDITIONS CROSSWALK 
This page has been left blank for double-sided copying. 
We studied the prevalence of conditions measurable in the NHIS that are most prevalent or had substantial growth among recent SSDI and SSI beneficiaries. To do so, we first reviewed primary diagnoses of adult SSDI and SSI and child SSI beneficiaries, in recent years and historically, as reported in SSA's 2016 Annual Statistical Report (SSA 2016). These primary diagnoses do not reflect the full health of beneficiaries; many beneficiaries have multiple health conditions.

We identified 19 diagnostic groups or conditions that have relatively greater prevalence or recent growth: (1) musculoskeletal system and connective tissue, (2) mood disorders, (3) nervous system and sense organs, (4) circulatory system, (5) intellectual disability, (6) schizophrenic and other psychotic disorders, (7) other mental disorders, (8) injury, (9) neoplasms (cancer), (10) endocrine, nutritional or metabolic diseases, (11) respiratory system, (12) genitourinary system, (13) digestive system, (14) infectious and parasitic diseases, (15) blood disorders, (16) skin conditions, (17) autism, (18) congenital anomalies, and (19) developmental disorders (Table A.1). Our criteria for selecting these conditions were somewhat subjective, and different researchers may have included or excluded one or more of these conditions.

Among these 19 diagnostic groups, we were able to map variables in the NHIS to identify adults in 10 of these diagnostic groups and children in 10 of these diagnostic groups (Table A.1). We also used reported body mass index (BMI) to develop estimates of overweight and obesity. We excluded some diagnostic groups for adults (schizophrenia, other psychotic disorders, intellectual disabilities, blood disorders, skin conditions, autism, congenital, developmental) and for children (musculoskeletal, mood, neoplasms, genitourinary, digestive, infectious and parasitic diseases) because of small sample size or lack of identification in the NHIS. We excluded injury due to the fact that many of the injuries identified in the NHIS are short-term and would likely not align with SSA definitions for disability determination.

We recognize that for almost all conditions, measurement in the NHIS or any survey is not perfectly aligned with SSA's definitions for disability determination. Some of the NHIS questions begin with "has a doctor ever told you" or "in the last 30 days" and may include conditions that are not chronic. Many individuals identified in the NHIS as having a condition may not experience symptoms severe enough to experience disability. For example, a child reported to have skin conditions may have eczema that is chronic but not disabling. On the other hand, many individuals with disabilities severe enough to qualify for federal disability benefits may not be captured by any of the NHIS measures. Nevertheless, the NHIS provides annual data over 20 years that can shed light on whether population prevalence of these conditions has changed over time. 


\section{Table A.1. Condition prevalence among federal disability beneficiaries and measurement in NHIS}

\begin{tabular}{|c|c|c|c|}
\hline $\begin{array}{l}\text { Primary disabling } \\
\text { condition for SSA } \\
\text { benefits }\end{array}$ & $\begin{array}{c}\text { Adult } \\
\text { SSDI/SSI } \\
2016(\%)\end{array}$ & $\begin{array}{l}\text { Child SSI } \\
2016(\%)\end{array}$ & NHIS measures \\
\hline $\begin{array}{l}\text { Musculoskeletal } \\
\text { system and connective } \\
\text { tissue }\end{array}$ & $32.3 / 14.4$ & 0.8 & $\begin{array}{l}\text { (Adults only) } \\
\text { - Ever told had arthritis, rheumatoid arthritis, gout, lupus, } \\
\text { or fibromyalgia } \\
\text { - Over the past } 3 \text { months, had pain in jaw, front of ear, } \\
\text { lower back, lower back spreading to legs, or neck }\end{array}$ \\
\hline Mood disorders & $14.2 / 15.9$ & 3.2 & $\begin{array}{l}\text { (Adults only) In the past } 30 \text { days, felt: } \\
\text { - everything an effort } \\
\text { - feelings interfered with life } \\
\text { - hopeless } \\
\text { - nervous } \\
\text { - restless } \\
\text { - sad } \\
\text { - worthless }\end{array}$ \\
\hline $\begin{array}{l}\text { Nervous system and } \\
\text { sense organs }\end{array}$ & $9.4 / 7.9$ & 7.9 & $\begin{array}{l}\text { - Had frequent headaches/migraines in past } 12 \text { months } \\
\text { - Had severe headaches/migraines in past } 3 \text { months } \\
\text { - Had seizures in past } 12 \text { months } \\
\text { - Ever told had a stroke } \\
\text { - Quality of hearing without hearing aid } \\
\text { - Has trouble seeing }\end{array}$ \\
\hline Circulatory system & $8.1 / 4.3$ & 0.4 & $\begin{array}{l}\text { Ever told had: } \\
\text { - angina pectoris } \\
\text { - coronary heart disease } \\
\text { - heart condition/disease } \\
\text { - hypertension } \\
\text { - other (non-congenital) heart condition } \\
\text { - congenital heart disease }\end{array}$ \\
\hline Intellectual disability & $4.0 / 18.8$ & 9.7 & $\begin{array}{l}\text { (children only) } \\
\text { - Ever told had mental retardation }\end{array}$ \\
\hline Neoplasms & $3.2 / 1.3$ & 0.9 & $\begin{array}{l}\text { (Adults only) } \\
\text { - Ever told had cancer }\end{array}$ \\
\hline $\begin{array}{l}\text { Endocrine, nutritional, } \\
\text { and metabolic diseases }\end{array}$ & $3.1 / 2.3$ & 0.8 & - Ever told had diabetes \\
\hline Respiratory system & $2.8 / 2.1$ & 2.0 & $\begin{array}{l}\text { Ever told had: } \\
\text { - asthma } \\
\text { - cystic fibrosis } \\
\text { - emphysema } \\
\text { In the past } 12 \text { months, had: } \\
\text { - sinusitis } \\
\text { - chronic bronchitis }\end{array}$ \\
\hline Genitourinary system & $1.8 / 1.1$ & 0.2 & $\begin{array}{l}\text { (Adults only) } \\
\text { - In the past } 12 \text { months, told had weak or failing kidneys }\end{array}$ \\
\hline Digestive system & $1.7 / 1.0$ & 1.3 & $\begin{array}{l}\text { (Adults only) } \\
\text { Ever told had: } \\
\text { - chronic liver condition } \\
\text { - ulcer } \\
\text { In the past } 12 \text { months, had: } \\
\text { - frequent diarrhea } \\
\text { - liver condition } \\
\text { - food allergy }\end{array}$ \\
\hline $\begin{array}{l}\text { Infectious and parasitic } \\
\text { diseases }\end{array}$ & $1.3 / 1.3$ & 0.1 & $\begin{array}{l}\text { (Adults only) } \\
\text { - Ever had hepatitis }\end{array}$ \\
\hline
\end{tabular}


TABLE A.1 (continued)

\begin{tabular}{|c|c|c|c|}
\hline $\begin{array}{l}\text { Primary disabling } \\
\text { condition for SSA } \\
\text { benefits }\end{array}$ & $\begin{array}{l}\text { Adult } \\
\text { SSDI/SSI } \\
2016(\%)\end{array}$ & $\begin{array}{l}\text { Child SSI } \\
2016(\%)\end{array}$ & NHIS measures \\
\hline Blood disorders & $0.3 / 0.4$ & 1.0 & $\begin{array}{l}\text { (children only) } \\
\text { - Had anemia in past } 12 \text { months } \\
\text { - Ever told had sickle cell anemia }\end{array}$ \\
\hline Skin conditions & $0.3 / 0.2$ & 0.2 & $\begin{array}{l}\text { (children only) } \\
\text { - Had skin allergy in past } 12 \text { months }\end{array}$ \\
\hline Autism & $0.2 / 2.6$ & 14.4 & $\begin{array}{l}\text { (children only) } \\
\quad \quad \text { Ever told had autism }\end{array}$ \\
\hline Congenital anomalies & $0.2 / 1.0$ & 5.5 & $\begin{array}{l}\text { (children only) } \\
\text { Ever told had: } \\
\text { - cerebral palsy } \\
\text { - } \text { Down syndrome } \\
\text { muscular dystrophy }\end{array}$ \\
\hline $\begin{array}{l}\text { Developmental } \\
\text { disorders }\end{array}$ & $0.1 / 0.8$ & 19.7 & $\begin{array}{l}\text { (children only) } \\
\text { Ever told had: } \\
\text { - } \quad \text { ADHD/ADD } \\
\text { - learning disability } \\
\text { other developmental delay }\end{array}$ \\
\hline Overweight & n.a. & n.a. & - BMI 25 and over \\
\hline Obesity & n.a. & n.a. & - BMI 30 and over \\
\hline
\end{tabular}


This page has been left blank for double-sided copying. 
APPENDIX B

MEASURES OF FUNCTIONING 
This page has been left blank for double-sided copying. 
We used measures in the NHIS to create composite measures of functioning. We followed a conceptual framework that has been used in the literature for adults (Iezzoni et al. 2014). For adults, we constructed composite functioning measures across four domains of basic action difficulties (BADs): movement, sensory, emotional, and cognitive; and three complex activity limitations (CALs): self-care limitation, social limitation, and work limitation (Table B.1).

When possible, we measured the same BADs and CALs among children. However, one BAD (emotional) and two CALs (social limitation and work limitation) do not apply to or are not measurable for children. Instead, we included two child-specific CALs, school limitation and play limitation, as defined in Table B.1.

Table B.1. Composite measures of functioning

\begin{tabular}{|c|c|c|c|}
\hline & $\begin{array}{l}\text { Measured } \\
\text { among } \\
\text { adults }\end{array}$ & $\begin{array}{l}\text { Measured } \\
\text { among } \\
\text { children }\end{array}$ & NHIS measures \\
\hline \multicolumn{4}{|c|}{ Basic Action Difficulties } \\
\hline Movement & $x$ & $x$ & $\begin{array}{l}\text { - (Adults only) Any difficulty reported for performing one or } \\
\text { more of eight items by self without special equipment: } \\
\circ \text { Walk a quarter of a mile } \\
\circ \text { Walk up } 10 \text { steps without resting } \\
\circ \text { Stand or be on feet for about } 2 \text { hours } \\
\circ \text { Sit for about } 2 \text { hours } \\
\circ \text { Stoop, bend, or kneel } \\
\circ \text { Reach up over head } \\
\circ \text { Use fingers to grasp or handle small objects } \\
\circ \text { Lift or carry something as heavy as } 10 \text { pounds like a } \\
\text { bag of groceries } \\
\text { (Children only) Difficulty walking without special equipment } \\
\text { because of a health problem }\end{array}$ \\
\hline Sensory & $x$ & $x$ & $\begin{array}{l}\text { - Reports being blind or having trouble seeing even when } \\
\text { wearing glasses or contact lenses, or } \\
\text { - Reports being deaf or having a lot of trouble hearing without a } \\
\text { hearing aid, or } \\
\text { - (Adults only) Has ever worn a hearing aid }\end{array}$ \\
\hline Emotional & $x$ & & $\begin{array}{l}\text { - (Adults only) A score of } 13 \text { or higher based on responses of } \\
\text { "all of the time" ( } 4 \text { points), "most of the time" ( } 3 \text { points), "some } \\
\text { of the time" ( } 2 \text { points), "a little of the time" ( } 1 \text { point) to the } \\
\text { questions asking "During the past } 30 \text { days, how often did you } \\
\text { feel: } \\
\text { O So sad that nothing could cheer you up? } \\
\circ \text { Nervous? } \\
\circ \text { Restless or fidgety? } \\
\circ \text { Hopeless? } \\
\circ \text { That everything was an effort? } \\
\text { Worthless? }\end{array}$ \\
\hline Cognitive & $\mathrm{x}$ & $x$ & $\begin{array}{l}\text { Reports being limited in any way because of difficulty } \\
\text { remembering or because of experiencing periods of } \\
\text { confusion }\end{array}$ \\
\hline \multicolumn{4}{|c|}{ Complex Activity Limitations } \\
\hline Self-care limitation & $\mathrm{x}$ & $x$ & $\begin{array}{l}\text { - Requires help with any activities of daily living } \\
\text { - (Adults only) Requires help with any instrumental activities of } \\
\text { daily living }\end{array}$ \\
\hline Social limitation & $x$ & & $\begin{array}{l}\text { - (Adults only) Cannot do the following by self and without } \\
\text { special equipment or it is somewhat or very difficult: } \\
\text { Go out for things like shopping, movies, or sporting } \\
\text { events }\end{array}$ \\
\hline
\end{tabular}


TABLE B.1 (continued)

\begin{tabular}{|c|c|c|c|}
\hline & $\begin{array}{l}\text { Measured } \\
\text { among } \\
\text { adults }\end{array}$ & $\begin{array}{l}\text { Measured } \\
\text { among } \\
\text { children }\end{array}$ & NHIS measures \\
\hline & & & $\begin{array}{l}\text { Participate in social activities such as visiting friends, } \\
\text { attending clubs and meetings, going to parties } \\
\text { Do things to relax at home or for leisure (reading, } \\
\text { watching TV, sewing, listening to music) }\end{array}$ \\
\hline Work limitation & $x$ & & $\begin{array}{l}\text { (Adults only) Physical, mental, or emotional problem keeps } \\
\text { them from working at a job or business, or } \\
\text { (Adults only) Limited in kind or amount of work because of a } \\
\text { physical, mental, or emotional problem }\end{array}$ \\
\hline School limitation & & $x$ & $\begin{array}{l}\text { (Children only) Receives special education or early intervention } \\
\text { services }\end{array}$ \\
\hline Play limitation & & $x$ & $\begin{array}{l}\text { (Children only) Limited in kind or amount of play activities } \\
\text { because of a physical, mental, or emotional problem }\end{array}$ \\
\hline
\end{tabular}


APPENDIX C

SAMPLE CHARACTERISTICS BY YEAR 
This page has been left blank for double-sided copying. 
Table C.1. Sample characteristics by year

\begin{tabular}{|c|c|c|c|c|c|c|c|c|c|c|}
\hline & \multicolumn{5}{|c|}{ Adults $(\mathrm{N}=509,937)$} & \multicolumn{5}{|c|}{ Children $(\mathrm{N}=252,026)$} \\
\hline & Age & Female & White & Black & Other race & Age & Female & White & Black & Other race \\
\hline \multirow[t]{2}{*}{1997} & 38.83 & 0.509 & 0.821 & 0.120 & 0.0598 & 8.471 & 0.488 & 0.771 & 0.156 & 0.0730 \\
\hline & $(0.114)$ & $(0.00347)$ & $(0.00393)$ & $(0.00312)$ & $(0.00237)$ & $(0.0521)$ & $(0.00456)$ & $(0.00534)$ & $(0.00454)$ & (0.00308) \\
\hline \multirow[t]{2}{*}{1998} & 39.02 & 0.509 & 0.816 & 0.120 & 0.0641 & 8.489 & 0.488 & 0.769 & 0.154 & 0.0768 \\
\hline & $(0.104)$ & $(0.00350)$ & $(0.00383)$ & $(0.00333)$ & $(0.00217)$ & $(0.0548)$ & (0.00499) & $(0.00561)$ & $(0.00513)$ & $(0.00312)$ \\
\hline \multirow[t]{2}{*}{1999} & 39.17 & 0.511 & 0.808 & 0.118 & 0.0738 & 8.527 & 0.489 & 0.758 & 0.147 & 0.0954 \\
\hline & (0.109) & $(0.00374)$ & $(0.00381)$ & $(0.00315)$ & $(0.00237)$ & $(0.0565)$ & $(0.00547)$ & $(0.00560)$ & $(0.00474)$ & $(0.00353)$ \\
\hline \multirow[t]{2}{*}{2000} & 39.30 & 0.511 & 0.798 & 0.119 & 0.0832 & 8.533 & 0.488 & 0.742 & 0.148 & 0.110 \\
\hline & $(0.107)$ & $(0.00369)$ & $(0.00364)$ & $(0.00301)$ & $(0.00$ & (0.0545) & (0.00510) & $(0.00569)$ & $(0.00472)$ & $(0.00370)$ \\
\hline \multirow[t]{2}{*}{2001} & 39.43 & 0.510 & 0.795 & 0.119 & 0.08 & 8.548 & 0.489 & 0.744 & 0.147 & 0.109 \\
\hline & $(0.112)$ & $(0.00363)$ & $(0.00400)$ & $(0.00333)$ & $(0.002$ & $(0.0531)$ & $(0.00531)$ & $(0.00602)$ & $(0.00512)$ & $(0.00379)$ \\
\hline \multirow[t]{2}{*}{2002} & 39.59 & 0.510 & 0.796 & 0.120 & 0.0 & 8.56 & 0.489 & 0.745 & 0.145 & 0.1 \\
\hline & $(0.124)$ & $(0.00399)$ & $(0.00423)$ & $(0.0036$ & $(0.00$ & $(0.05$ & $(0.00543)$ & $(0.00620)$ & $(0.00$ & $(0.00$ \\
\hline \multirow[t]{2}{*}{2003} & 39.76 & 0.509 & 0.826 & 0.120 & 0.05 & 8.601 & 0.489 & 0.776 & 0.152 & 0.0721 \\
\hline & $(0.124)$ & (0.00399) & $(0.00413)$ & $(0.00361)$ & $(0.00$ & $(0.05$ & (0.00586) & $(0.00652)$ & $(0.00610)$ & (0.00333) \\
\hline \multirow[t]{2}{*}{2004} & 39.91 & 0.508 & 0.820 & 0.121 & 0.0 & 8.60 & 0.489 & 0.773 & 0.1 & \\
\hline & $(0.119$ & $(0.00381)$ & $(0.00384)$ & $(0.00350)$ & $(0.00$ & $(0.0$ & (0.00568) & $(0.00549)$ & $(0.00$ & $(0.0$ \\
\hline \multirow[t]{2}{*}{2005} & 40.06 & 0.508 & 0.821 & 0.120 & 0.05 & 8.612 & 0.489 & 0.775 & 0.15 & 0.0730 \\
\hline & (0.116) & $(0.00361)$ & $(0.00392)$ & $(0.00325)$ & $(0.00$ & (0.05 & $(0.00529)$ & $(0.00592)$ & $(0.00$ & $(0.00$ \\
\hline \multirow[t]{2}{*}{2006} & 40.13 & 0.507 & 0.806 & 0.125 & 0.0694 & 8.580 & 0.489 & 0.762 & 0.156 & 0.0824 \\
\hline & $(0.143)$ & $(0.00421)$ & $(0.00429)$ & $\left(0.003^{\prime}\right.$ & $(0.00$ & $(0.06$ & (0.00693) & (0.00619) & $(0.00$ & $(0.00$ \\
\hline \multirow[t]{2}{*}{2007} & 40.27 & 0.506 & 0.800 & 0.125 & 0.075 & 8.565 & 0.489 & 0.756 & 0.155 & 0.0886 \\
\hline & $(0.155)$ & $(0.00466)$ & $(0.00458)$ & $(0.00390)$ & $(0.00$ & (0.0690) & (0.00677) & $(0.00696)$ & $(0.00$ & $(0.00$ \\
\hline \multirow[t]{2}{*}{2008} & 40.34 & 0.507 & 0.802 & 0.126 & 0.0719 & 8.538 & 0.489 & 0.754 & 0.15 & 0.0922 \\
\hline & $(0.153)$ & $(0.00489)$ & $(0.00475)$ & $(0.00426)$ & $(0.00268)$ & (0.074 & (0.00678) & $(0.00713)$ & (0.006 & (0.00446) \\
\hline \multirow[t]{2}{*}{2009} & 40.51 & 0.507 & 0.799 & 0.127 & 0.0731 & 8.480 & 0.489 & 0.758 & 0.153 & 0.0888 \\
\hline & $(0.146)$ & $(0.00407)$ & $(0.00440)$ & $(0.00367)$ & $(0.00266)$ & (0.0680) & $(0.00631)$ & $(0.00567)$ & $(0.00513)$ & $(0.00$ \\
\hline \multirow[t]{2}{*}{2010} & 40.55 & 0.506 & 0.797 & 0.128 & 0.0749 & 8.404 & 0.489 & 0.754 & 0.148 & 0.0975 \\
\hline & $(0.135)$ & $(0.00439)$ & $(0.00442)$ & $(0.00387)$ & $(0.00250)$ & $(0.0604)$ & $(0.00633)$ & $(0.00586)$ & $(0.00510)$ & $(0.00396)$ \\
\hline \multirow[t]{2}{*}{2011} & 40.62 & 0.506 & 0.796 & 0.127 & 0.077 & 8.425 & 0.489 & 0.752 & 0.14 & 0.101 \\
\hline & $(0.127)$ & $(0.00377)$ & $(0.00390)$ & $(0.00328)$ & $(0.002$ & (0.0533) & (0.00548) & $(0.00550)$ & $(0.004$ & $(0.00$ \\
\hline \multirow[t]{2}{*}{2012} & 40.71 & 0.510 & 0.789 & 0.126 & 0.0846 & 8.584 & 0.489 & 0.747 & 0.144 & 0.109 \\
\hline & $(0.122)$ & $(0.00416)$ & $(0.00374)$ & $(0.00298)$ & $(0.00238)$ & & (0.00527) & (0.00559) & $(0.00441)$ & (0.00404) \\
\hline \multirow[t]{2}{*}{2013} & 40.76 & 0.510 & 0.786 & 0.128 & 0.0858 & 8.547 & 0.489 & 0.745 & 0.148 & 0.107 \\
\hline & $(0.138)$ & $(0.00434)$ & $(0.00381)$ & $(0.00310)$ & $(0.00264)$ & $(0.0560)$ & $(0.00592)$ & $(0.00585)$ & $(0.00472)$ & $(0.00375)$ \\
\hline \multirow[t]{2}{*}{2014} & 40.79 & 0.509 & 0.782 & 0.131 & 0.0871 & 8.551 & 0.489 & 0.742 & 0.148 & 0.109 \\
\hline & (0.139) & $(0.00434)$ & $(0.00397)$ & $(0.00334)$ & $(0.00259)$ & $(0.0580)$ & (0.00647) & $(0.00598)$ & (0.00489) & (0.00398) \\
\hline \multirow[t]{2}{*}{2015} & 40.81 & 0.509 & 0.777 & 0.131 & 0.0921 & 8.606 & 0.490 & 0.741 & 0.147 & 0.112 \\
\hline & $(0.145)$ & $(0.00413)$ & $(0.00412)$ & $(0.00342)$ & $(0.00274)$ & $(0.0580)$ & (0.00618) & $(0.00654)$ & $(0.00524)$ & $(0.00403)$ \\
\hline 2016 & 40.86 & 0.509 & 0.773 & 0.130 & 0.0969 & 8.571 & 0.490 & 0.737 & 0.147 & 0.116 \\
\hline & $(0.140)$ & $(0.00423)$ & $(0.00634)$ & $(0.00499)$ & $(0.00372)$ & $(0.0629)$ & $(0.00670)$ & $(0.00728)$ & $(0.00605)$ & $(0.00464)$ \\
\hline 2017 & 40.86 & 0.508 & 0.765 & 0.132 & 0.103 & 8.618 & 0.490 & 0.732 & 0.147 & 0.121 \\
\hline & $(0.156)$ & $(0.00462)$ & $(0.00740)$ & $(0.00590)$ & $(0.00465)$ & $(0.0695)$ & $(0.00597)$ & $(0.00868)$ & $(0.00720)$ & $(0.00579)$ \\
\hline
\end{tabular}


This page has been left blank for double-sided copying. 
www.mathematica-mpr.com

Improving public well-being by conducting high quality, objective research and data collection

PRINCETON, NJ | ANN ARBOR, MI | CAMBRIDGE, MA | CHICAGO, IL | OAKLAND, CA TUCSON, AZ - SEATTLE, WA - WASHINGTON, DC - WOODLAWN, MD

\section{MATHEMATICA CENTER FOR} STUDYING DISABILITY POLICY

Mathematica ${ }^{\circledast}$ is a registered trademark

of Mathematica Policy Research, Inc. 